\title{
Indications for cardiovascular magnetic resonance in children with congenital and acquired heart disease: an expert consensus paper of the Imaging Working Group of the AEPC and the Cardiovascular Magnetic Resonance Section of the EACVI
}

\author{
E.R. Valsangiacomo Buechel, ${ }^{1 *}$ L. Grosse-Wortmann, ${ }^{2}$ S. Fratz, ${ }^{3}$ J. Eichhorn, ${ }^{4}$ S. Sarikouch, ${ }^{5}$ G.F. Greil, ${ }^{6,7}$
} P. Beerbaum, ${ }^{8}$ C. Bucciarelli-Ducci, ${ }^{9}$ B. Bonello, ${ }^{10}$ L. Sieverding, ${ }^{11}$ J. Schwitter, ${ }^{12}$ W.A. Helbing, ${ }^{13}$ Document reviewers: EACVI: Maurizio Galderisi, (Italy), Owen Miller, (UK), Rosa Sicari, (Italy), John Simpson, (UK), Erik Thaulow, (Norway), Thor Edvardsen, (Norway), AEPC: Konrad Brockmeier, (Germany), Shakeel Qureshi, (UK), and Joerg Stein, (Austria)

${ }^{1}$ Division of Paediatric Cardiology, Department of Paediatrics and Children's Research Centre, University Children's Hospital Zurich, Steinwiesstrasse 75, 8032 Zurich, Switzerland; ${ }^{2}$ The Labatt Family Heart Centre, Department of Paediatrics, The Hospital for Sick Children, University of Toronto, Toronto, Canada; ${ }^{3}$ Department of Paediatric Cardiology and Congenital Heart Disease, Deutsches Herzzentrum München, Klinikum an der Technischen Universität München, Munich, Germany; ${ }^{4}$ Department of Paediatric, Klinikum Leverkusen, Leverkusen, Germany; ${ }^{5}$ Department of Cardiothoracic, Transplantation, and Vascular Surgery, Hannover Medical School, Hannover, Germany; ${ }^{6}$ Division of Imaging Sciences and Biomedical Engineering, Rayne Institute, St Thomas' Hospital, London, UK; 'Department of Congenital Heart Disease, Evelina Children's Hospital, London, UK; ${ }^{8}$ Department of Paediatric Cardiology and Paediatric Intensive Care Medicine, Children's Hospital, Hannover Medical University, Hannover, Germany; ${ }^{9}$ Department of Cardiology, Bristol Heart Institute, NIHR Bristol Cardiovascular Biomedical Research Unit, Bristol and Cardiovascular Magnetic Resonance Unit, Royal Brompton Hospital, NIHR Brompton Cardiovascular Biomedical Research Unit, National Heart and Lung Institute, Imperial College, London, UK; ${ }^{10}$ Division of Cardiology, Timone Children's Hospital, Aix-Marseille University, Marseille, France; ${ }^{11}$ Department of Paediatric Cardiology, University Children's Hospital, Tuebingen, Germany; ${ }^{12}$ Department of Internal Medicine, Division of Cardiology and Cardiac MR Center, University Hospital of Lausanne, Lausanne, Switzerland; ${ }^{13}$ Department of Paediatrics, Division of Paediatric Cardiology and Radiology, Erasmus University Medical Centre, Sophia Children's Hospital, Rotterdam, The Netherlands

This article provides expert opinion on the use of cardiovascular magnetic resonance (CMR) in young patients with congenital heart disease (CHD) and in specific clinical situations. As peculiar challenges apply to imaging children, paediatric aspects are repeatedly discussed. The first section of the paper addresses settings and techniques, including the basic sequences used in paediatric CMR, safety, and sedation. In the second section, the indication, application, and clinical relevance of CMR in the most frequent CHD are discussed in detail. In the current era of multimodality imaging, the strengths of CMR are compared with other imaging modalities. At the end of each chapter, a brief summary with expert consensus key points is provided. The recommendations provided are strongly clinically oriented. The paper addresses not only imagers performing CMR, but also clinical cardiologists who want to know which information can be obtained by CMR and how to integrate it in clinical decision-making.

Keywords: Expert consensus paper; Congenital heart disease; Cardiovascular magnetic resonance imaging

Received: 10 May 2014; Accepted: 2 June 2014; First published online: 5 March 2015

*Correspondence to: Tel: +41 44266 7339; Fax: +41 44266 7981; E-mail: valsangiacomo@kispi.uzh.ch, Emanuela.valsangiacomo@kispi.uzh.ch Published on behalf of the European Society of Cardiology. All rights reserved. @ The Author 2015. 
A S A RESULT OF SPECTACULAR IMPROVEMENTS IN diagnostics and treatment options, survival of patients with congenital heart disease (CHD) has increased dramatically. However, long-term morbidity and mortality are substantial as is the need for reinterventions. ${ }^{1}$

Imaging features prominently in the pre and postoperative management of patients with CHD. Diagnostic accuracy, burden to the patient, availability, and economics all have a role in the choice of the appropriate imaging modality in clinical practice. Echocardiography remains the mainstay of cardiovascular diagnostics, but other techniques are gaining in importance, particularly cardiovascular magnetic resonance (CMR) and computed tomography (CT; Table 1). Existing expert opinion-based guidelines, focused on adult populations, for the proper utilization of CMR are available. ${ }^{2}$ Specific challenges apply to imaging children and adolescents with CHD. These include the even more pressing need to avoid the use of ionizing radiation, assessment of anatomy that is often complex and involves small structures, as well as imaging at fast heart rates. The current paper aims to express the consensus among experts in the field of paediatric CMR regarding its use in young patients with CHD. It is beyond the scope of this paper to discuss all technical details of CMR imaging in CHD, which have been addressed elsewhere recently, ${ }^{3}$ much more to describe the use of CMR in specific paediatric clinical situations.

\section{Settings and techniques}

In contrast to scanning adults with ischaemic heart disease, the CMR approach to paediatric patients with CHD has to be individualized and nearly all sequences need to be adapted to the patient's size, age, heart rate and, of course, the specific clinical question. ${ }^{4,5}$ Therefore, it is of critical importance that CMR studies of young patients with CHD are performed in centres with expertise in both the haemodynamic situation at hand and the CMR technique used. ${ }^{4,5}$ The presence of an expert CMR reader throughout the length of the study is typically required, as each heart is different and the subsequent imaging steps need to be individually tailored upon on the findings observed. High-quality results can be achieved only with a commitment to invest time and resources for sometimes lengthy scans and laborious post-processing of the data. Requirements regarding dedicated training for performing congenital CMR have been published. ${ }^{6}$ Requirements for institutional accreditation, and particularly regarding a minimal case load, are available for adult general CMR in Europe, but are still lacking for paediatric heart disease and for $\mathrm{CHD}^{7}$

\section{Basic sequences used in paediatric CMR}

The sequences utilized in routine paediatric CMR can be divided into three main categories, following their purpose: to define morphology, to assess function,

Table 1. Comparison of available imaging modalities for assessment of different conditions.

\begin{tabular}{|c|c|c|c|c|}
\hline & Echo & CMR & $\mathrm{CT}$ & Catheterization \\
\hline Aortic arch & ++ & +++ & +++ & +++ \\
\hline Pulmonary arteries & ++ & +++ & +++ & +++ \\
\hline Pulmonary veins & ++ & $\begin{array}{l}+++ \\
\text { Precise anatomical information } \\
\quad+\text { flow measurements }\end{array}$ & ++ & $\begin{array}{l}+++ \\
\text { Wedge pressure }\end{array}$ \\
\hline AV valves & +++ & + & $(+)$ & $\begin{array}{l}+ \\
\text { Pressure gradients }\end{array}$ \\
\hline Semilunar valves & +++ & $\begin{array}{l}++ \\
\text { Quantification of regurgitation }\end{array}$ & + & $\begin{array}{l}+ \\
\text { Pressure gradients }\end{array}$ \\
\hline Complex CHD & ++ & $\begin{array}{l}+++ \\
\text { Precise anatomical information } \\
\quad+\text { flow measurements }\end{array}$ & ++ & $\begin{array}{l}++ \\
\text { Pulmonary arterial pressure }\end{array}$ \\
\hline Coronary arteries & $\begin{array}{l}+ \\
\text { Only proximal } \\
\text { segments }\end{array}$ & ++ & +++ & $\begin{array}{l}+++ \\
\text { Gold standard }\end{array}$ \\
\hline $\begin{array}{l}\text { Tissue characterization (tumours } \\
\text { and cardiomyopathies) }\end{array}$ & + & +++ & + & $(+)$ \\
\hline Ventricular function & ++ & +++ & $\begin{array}{l}(+) \\
\text { ECG-gated CT }\end{array}$ & ++ \\
\hline Flow measurements & + & +++ & - & - \\
\hline Shunt quantification & + & +++ & - & +++ \\
\hline
\end{tabular}

(+): limited application, major limitations; $+:$ can be used in the assessment of this lesion, but has some significant limitations and better alternatives are available; ++: useful ommonly applied in the assessment of the lesion, and it may present some limitation; +++: technique of choice for the assessment of the lesion; - : cannot be adequately with this modality. 
Table 2. Summary of the sequences recommended for imaging different conditions.

\begin{tabular}{|c|c|c|c|c|c|c|c|}
\hline \multirow[b]{2}{*}{ Lesion } & \multirow[b]{2}{*}{ BB SE } & \multirow[b]{2}{*}{ 2D SSFP } & \multicolumn{3}{|c|}{ CMR sequence } & \multirow[b]{2}{*}{ Perfusion imaging } & \multirow[b]{2}{*}{ LGE } \\
\hline & & & PC flow & 3D CE-MRA & 3D SSFP & & \\
\hline Aortic arch anomaly & + & ++ & ++ & +++ & $++*$ & & \\
\hline Pulmonary arteries & + & + & ++ & +++ & $++*$ & & \\
\hline Pulmonary veins & + & + & + & +++ & $++*$ & & \\
\hline Shunt lesions & ++ & ++ & +++ & ++ & & & \\
\hline TOF & ++ & +++ & +++ & ++ & $++*$ & & ++ \\
\hline Complex CHD & ++ & +++ & +++ & ++ & +++ & & \\
\hline Single ventricles & ++ & +++ & +++ & ++ & $++*$ & & ++ \\
\hline Intracardiac tumours & ++ & ++ & & & & +++ & ++ \\
\hline Cardiomyopathies & + & ++ & ++ & & & ++ & +++ \\
\hline Coronary arteries & & & & & ++ & +++ & ++ \\
\hline
\end{tabular}

$+:$ may be used in the assessment of this lesion, but better alternatives available or does not provide additional information over other techniques; ++ : useful technique, commonly applied in the assessment of the lesion; +++ : needs to be part of any study in this lesion.

*If contrast needs to be avoided. BB SE, Black blood spin-echo.

including ventricular volumes and blood flow, and to define myocardial tissue properties, including myocardial perfusion as well as fibrosis. Recommendations for sequences to be used for a given lesion are summarized in Table 2.

Anatomical imaging. In spin-echo imaging pulse sequences (often referred to as 'darkblood' or 'blackblood' sequences), flowing blood appears dark whereas stationary tissues appear as varying shades of grey. ${ }^{8}$ The main advantage of spin-echo sequences is that they are less susceptible to artefacts caused by turbulent flow and metallic implants. ${ }^{9}$ Respiratory motion is usually addressed by breath-holding, multiple averages, or diaphragm tracking.

In steady-state free precession (SSFP) acquisitions, blood appears bright. Images can be displayed as a cine loop. 8 Two-dimensional (2D) SSFP is the most frequently used sequence for anatomical imaging in $\mathrm{CHD}$, as it allows views in any desired plane and adds qualitative information about function and valve motion. Image acquisition is usually performed during breath-holding. However, images can also be acquired during free-breathing in most paediatric patients. Cardiac motion is usually controlled by means of retrospective gating to ECG as this allows including the end-diastolic heart phase, as opposed to prospective ECG-triggering.

Contrast-enhanced magnetic resonance angiography (CE-MRA) uses intravenously administered gadolinium-based contrast agents to reduce $T_{1}$ relaxation time of blood and improve the contrast between the blood pool and the surrounding tissue. $^{10,11}$ The increased contrast (signal) allows adjusting the acquisition parameters for obtaining high-resolution images. ${ }^{12,13}$ The dataset - a full volume composed of a stack of contiguous slices - can be reconstructed in any desired oblique plane (multiplanar reformats and maximum intensity projection images) or volume-rendered in a threedimensional (3D) image. For optimal quality of the CE-MRA images, the sequence and particularly the timing of image acquisition need to be designed for the clinical question and the vessels that need to be assessed. Even in small children, high spatial resolution with submillimetre resolution can be achieved with CE-MRA in which the images are acquired during breath-holding. ${ }^{14,15}$ Using this technique, even subtle variations in luminal diameters can be detected. Thus, CE-MRA has become widely accepted in the diagnosis of vascular disease in children, and cardiac catheterization can frequently be avoided. . $^{3,16,17}$

CE-MRA is acquired without ECG-triggering and the reconstructed images represent an average appearance over the cardiac cycle. For this reason the edges of pulsatile vascular structures, such as the aortic root, as well as the coronaries appear blurry.

In time-resolved MR angiography techniques, the dynamic distribution of contrast medium into the pulmonary vasculature can be observed. Without dedicated timing of image acquisition, artefacts from motion are minimized and separation of arteries and veins is possible. ${ }^{18}$

3D SSFP is an ECG-triggered pulse sequence with respiratory motion compensation by diaphragmatic navigators ${ }^{19-21}$ or navigation on the heart itself, called self-navigation. ${ }^{19}$ These sequences can be combined with contrast media or not and produce a high-resolution 3D dataset of the whole heart and intrathoracic vasculature. ${ }^{20-22}$ Owing to the double gating (ECG and respiratory), cardiovascular structures close to the heart, such as the aortic bulb and the proximal coronary arteries, can be delineated very clearly. ${ }^{19,23,24}$ Image reconstruction is usually performed using multiplanar reformatting. 
Functional imaging. Ventricular volumes and ejection fraction are assessed by acquisition of a stack of SSFP cine slices (as described above) covering the entire heart. ${ }^{8}$ The stack can be aligned in a ventricular short-axis plane parallel to the atrioventricular valves or perpendicular to the ventricular septum or in an axial plane transverse to the thorax. ${ }^{25-28}$ Measurements should be performed consistently using the same orientation, as results from short axis and axial orientations are not interchangeable. On the stack of cine slices, end-diastolic and -systolic volumes and mass of both ventricles are derived by contouring the endocardial and epicardial borders. This method is based on Simpson's summation of discs method with minimal geometrical assumption. This is of particular importance in the right ventricle or in functionally single ventricles. Normal values for both ventricles and both atria have been published in children, ${ }^{25-27,29}$ and high reproducibility of the measurements has been demonstrated in children with $\mathrm{CHD}$ and with normal hearts. ${ }^{25,30} \mathrm{~A}$ consensus policy regarding ventricular segmentation, i.e. inclusion or exclusion of papillary muscles and trabeculations, leads to an even better reproducibility of the measurements. ${ }^{31}$

Blood flow across a vessel can be measured accurately by using a velocity-encoded phase-contrast (PC) cine sequence. Typically, a slice is placed perpendicular to the vessel of interest. After contouring the vessel of interest, the volume of blood passing through the plane is calculated as the product of velocity and cross-sectional area. ${ }^{32}$ In general, when assessing $\mathrm{CHD}$, it is advisable to perform measurements in all large arteries, i.e. aorta, pulmonary trunk, and side branches, as well as in the caval veins and to compare the results for internal consistency.

First-pass myocardial perfusion imaging uses the dynamic inflow of gadolinium-based contrast medium into the myocardium to depict zones of decreased perfusion. Areas of reduced myocardial perfusion will remain dark, whereas normal perfusion shows a bright myocardial signal with the advent of gadolinium. The test can be performed at rest or under pharmacological stress for more clear depiction of ischaemia. $8,33,34$ The option to perform perfusion imaging at rest and during stress in combination with superior spatial resolution compared with single photon emission computed tomography (SPECT) makes it an attractive technique. ${ }^{35}$

Stress imaging assesses ventricular function by $2 \mathrm{D}$ SSFP under pharmacological stress with dobutamin or exercise stress with CMR-compatible equipment. Stress imaging is performed in some centres in selected borderline clinical situations to test contractile reserve of a systemic chamber, such as in a right ventricle in systemic position or in univentricular hearts. ${ }^{36}$

Late gadolinium enhancement (LGE), or myocardial delayed enhancement, is a technique demonstrating abnormal deposition of contrast agent within the myocardium late after contrast medium injection. The focal hyperenhanced areas represent regions of myocardial fibrosis. ${ }^{8}$ Fibrotic and necrotic areas in the myocardium appear bright on LGE images in contrast to the dark healthy myocardium. In children with CHD, LGE may result from scars after infarction, surgical scars in the myocardium, and/or from surgically placed patches. ${ }^{37}$

In younger children, obtaining adequate temporal and spatial resolutions may represent a technical challenge, as the structures of interest are smaller and heart rates higher than in adults. ${ }^{14}$

Expert consensus key points.

(i) Black-blood spin-echo, 2D SSFP, and 3D SSFP techniques as well as contrast-enhanced MR angiography are the most important sequences for anatomical imaging in CHD.

(ii) In children, higher spatial and temporal resolution is required to account for higher heart rates and smaller anatomical structures than in adults.

(iii) CMR is the current clinical gold standard for measurements of ventricular function and blood flow. Both are crucial components of a CMR examination in patients with CHD.

\section{Sedation and anaesthesia}

In younger children, typically before school-age, a CMR examination usually requires sedation or general anaesthesia. In young patients with complex $\mathrm{CHD}$, in spite of the burden of general anaesthesia, CMR can be utilized for completing diagnosis before surgical repair or for planning other therapeutic interventions, 5,14 and purely diagnostic cardiac catheter examination with its related potential complications can usually be avoided. ${ }^{38-40}$

The preferences and availability of sedation and/or general anaesthesia differ from centre to centre, and advantages and risks of each technique are discussed elsewhere. ${ }^{41,42}$ When sedation or general anaesthesia is used, appropriate monitoring of the patient and presence of an expert team which is versed in the administration of drugs and equipped to deal with emergencies is mandatory.

Even though patients under anaesthesia, infants younger than 1 year, inpatients, and ICU patients are at higher risk for adverse events during CMR than the general outpatient population, ${ }^{43}$ it has been shown that CMR can be safely performed even in critically ill infants, if carried out by a dedicated team. ${ }^{44}$ Careful analysis of the risks and benefits of a CMR examination under general anaesthesia needs to be performed before the procedure.

Certain patient groups, including those younger than 3 months of age, patients with a functional 
single-ventricle physiology, pulmonary hypertension, unrepaired cyanotic CHD, or airway pathology, may require hospitalization. ${ }^{45}$

\section{Expert consensus key points.}

(i) Dedicated staff and MR compatible equipment are necessary for performing general anaesthesia or deep sedation in children with CHD undergoing CMR.

(ii) In patients requiring anaesthesia or sedation, the risks and benefits of the procedure should be balanced carefully.

\section{Safety and contraindications}

Except for patients requiring general anaesthesia, the safety issues for CMR in children with CHD do not differ from those in general paediatric magnetic resonance imaging, and CMR is a safe imaging procedure. The main advantages of CMR are the lack of ionizing radiation and its non-invasiveness. Particularly, the use of radiation-free modalities is very important in children, as their risk for developing radiation-induced cancer is three to four times higher than in adults. ${ }^{46}$ Correspondingly, CMR has a favourable benefit/risk profile compared with cardiac catheterization and CT. ${ }^{47}$

The most important step to reduce potential risks of CMR scanning is to establish a strict policy of screening before CMR for the patient and all accompanying persons, including parents and medical personnel. ${ }^{48}$ This is particularly important to avoid the so-called missile effect caused by ferromagnetic objects drawn rapidly into the scanner by massive magnetic forces. ${ }^{49}$

Other potential safety issues related to CMR relate to hyperthermia, acoustic noise, implantable devices, and nephrogenic systemic fibrosis (NSF).

If used according to the manufacturer's recommendations, CMR at 1.5 or $3 \mathrm{~T}$ does not pose any safety concerns with regard to energy deposition and hyperthermia. ${ }^{50}$ Nevertheless, it is important to note that thermoregulatory mechanisms are immature in infants, abnormal in patients with cardiovascular disease, and can be influenced by some medications such as diuretics, calcium blockers, beta-blockers, amphetamines, and sedatives. Acoustic noise during CMR scanning can cause temporary or permanent hearing impairment. Adequate precautions to shield patients, including infants, should be taken at all times.

In general, most cardiovascular devices implanted nowadays are MR compatible and safe to be scanned. www.mrisafety.com provides specific safety information for specific devices and should be consulted before scanning. ${ }^{51}$ Cochlear implants and cerebrospinal fluid shunts are non-cardiovascular implants that may be present in CHD patients. CMR is contraindicated in patients who have a cochlear implant. Most cerebrospinal shunts are CMR compatible, but manufacturer-specific safety guidelines must be followed.

Cardiac pacemakers and implantable cardioverters/ defibrillators (ICDs) are generally considered a relative contraindication to entering the MR environment. ${ }^{52}$ CMR-compatible cardiac pacemakers have been recently developed and are currently undergoing testing. ${ }^{53}$

Severe complications of gadolinium-derived contrast agents are rare in paediatric patients. Common side effects include extravasation of the contrast agent and allergic reactions from mild skin rash to cardiovascular decompensation. NSF is a rare but serious condition that consists of fibrosis of skin, joints, eyes, and internal organs. ${ }^{54}$ The development of NSF has been linked to the biochemical structure of gadolinium-containing contrast agents in the presence of end-stage renal failure. Thus, all patients who are candidates for gadoliniumderived contrast medium administration must be screened for renal dysfunction, and in infants ionic macrocyclic contrast agents should be used. ${ }^{55,56}$

Expert consensus key points.

(i) CMR in children and adolescents with heart disease has a high safety profile.

(ii) Lack of radiation is the most striking advantage over other advanced imaging modalities.

(iii) Main contraindications for CMR in childhood are cochlear implants, old-generation pacemakers, ICDs, and other noncompatible implants.

(iv) The use of gadolinium-derived contrast agents is contraindicated in children with end-stage renal failure, due to the risk for developing NSF.

\section{Clinical applications}

\section{Aortic arch anomalies}

Common indications for performing CMR in anomalies of the aortic arch include vascular rings (Fig 1), interrupted aortic arch, truncus arteriosus communis, complex forms of aortic coarctation, and congenital connective tissue disorders, such as Marfan and Turner syndrome. ${ }^{57,58} \mathrm{CMR}$ can be performed at the time of diagnosis in order to refine an echocardiographic diagnosis and during follow-up after surgical correction or catheter intervention, when residual or recurrent stenoses and/or aneurysms need to be ruled out. $^{58-60}$ Stents in the aortic arch are not a contraindication for CMR; however, CMR is not suited to evaluate stent patency. The sequences used for imaging the aortic arch are summarized in Table 2.

The sensitivity of CMR techniques to detect vascular abnormalities is as good as that of conventional catheter angiocardiography (Table 1), so that cardiac catheterization can be reserved for selected cases and for catheter-guided interventions. ${ }^{61}$ 
(a)

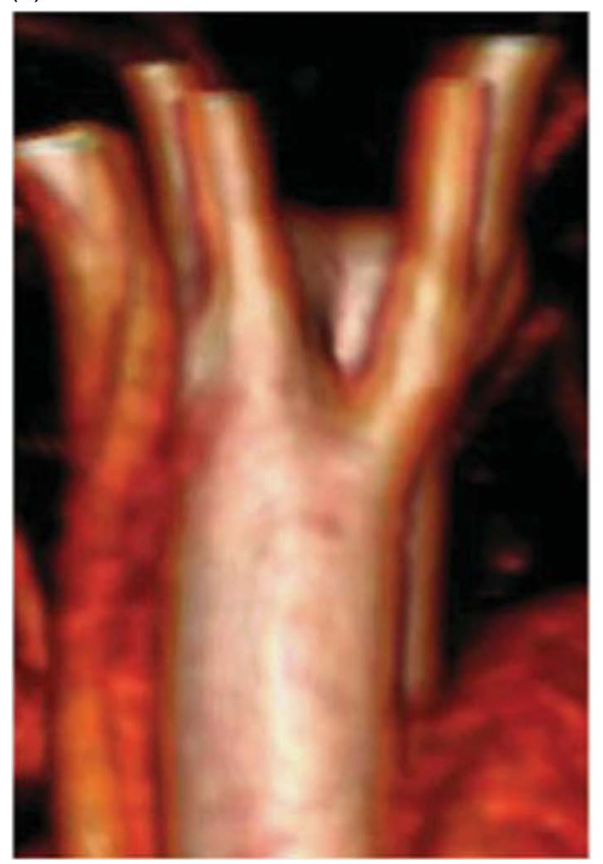

(b)

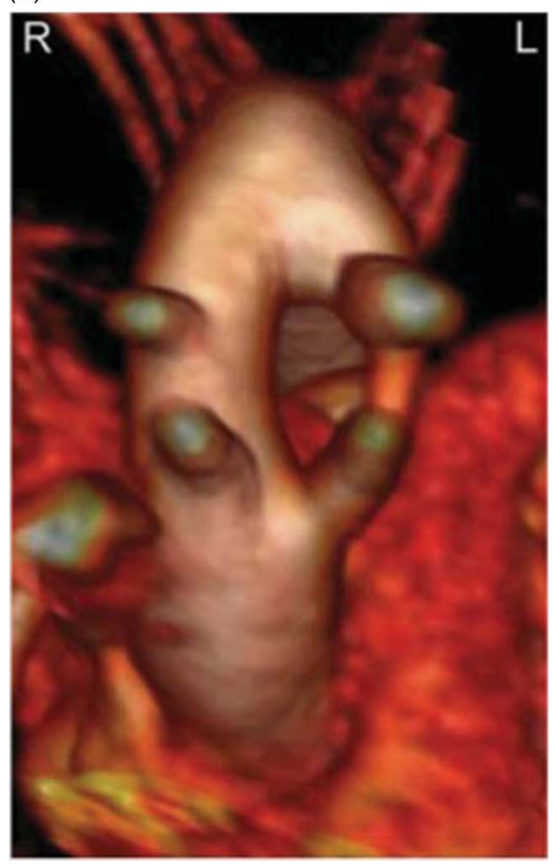

Figure 1.

Double aortic arch as shown in a $3 D$ reconstruction from a contrast-enhanced $M R$ angiography. View from the front (a) and from cranial (b).

The ability to generate 3D anatomical images by CEMRA or 3D SSFP allows decision-making on the most appropriate treatment technique, i.e. cardiac surgery or catheter-guided intervention. ${ }^{61-64} \mathrm{CT}$ angiography is a sound alternative particularly when associated airway anomalies are suspected and/or when the clinical scenario is that of a young and sick infant or neonate.

In coarctation of the aorta, haemodynamic assessment is performed with a velocity-encoded PC cine sequence using high velocity encoding typically of at least $200 \mathrm{~cm} / \mathrm{s}^{65}$ Flow measurements are usually performed in a perpendicular plane through the ascending aorta, proximal descending aorta (aortic isthmus, immediately distal to the stenosis), and at the level of the diaphragm. An increase in flow between the distal aortic arch and the descending aorta at the level of the diaphragm is indicative for significant collateral circulation. In addition, the velocity of the jet at the level of the stenotic isthmus, if PC measurement is performed accordingly, provides semi-quantitative information about the severity of vascular narrowing.

\section{Expert consensus key points.}

(i) CMR is the first-line advanced imaging technique beyond echocardiography for the anatomical assessment of aortic arch anomalies.

(ii) Reconstructed 3D CMR images are helpful for planning interventions of the aortic arch. (iii) CMR has an important role in follow-up after an intervention.

(iv) Blood flow measurements add functional information to the anatomical images.

\section{The pulmonary arteries}

The advantages of CMR imaging compared with other modalities are very good anatomical visualization of right ventricular outflow tract (RVOT), pulmonary bifurcation, and pulmonary side branches, combined with functional information. CMR is the only technique allowing quantitative flow measurements in the pulmonary arteries (Table 1). ${ }^{66}$

Anatomical imaging of the pulmonary arteries can be done by various angiographic techniques, as described above and in Table 2. ${ }^{57,67}$ CE-MRA has been validated against conventional angiography ${ }^{13}$ and has also been demonstrated to reliably detect aorto-pulmonary collateral arteries in tetralogy of Fallot (TOF) with severe pulmonary stenosis or atresia. ${ }^{16}$ Furthermore, CMR provides clear visualization of the spatial alignment of the pulmonary bifurcation, as well as of the relationship between the pulmonary arteries and the surrounding structures, as the airways and other vascular structures such as the aorta (Fig 2). ${ }^{67}$

Flow measurements by velocity-encoded PC cine add functional information to anatomical findings and are crucial for assessing the need for interventions (Fig 2). Flow redistribution in the pulmonary arteries has been observed not only in the presence of 
(a)

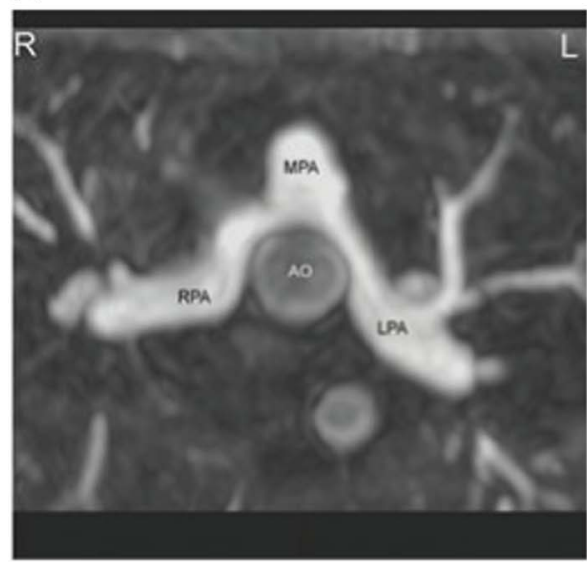

(b)

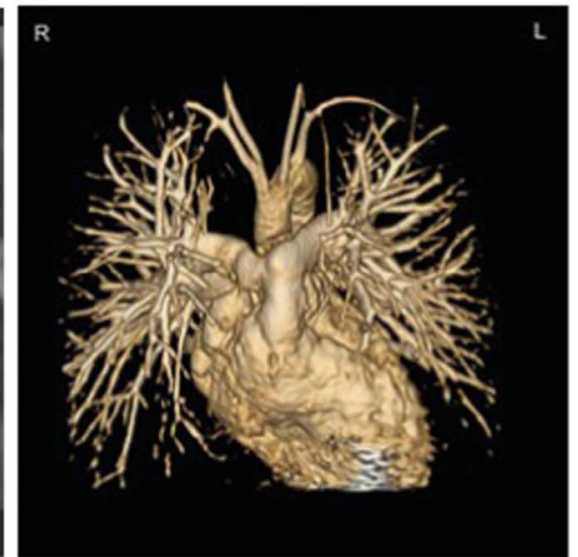

(c)

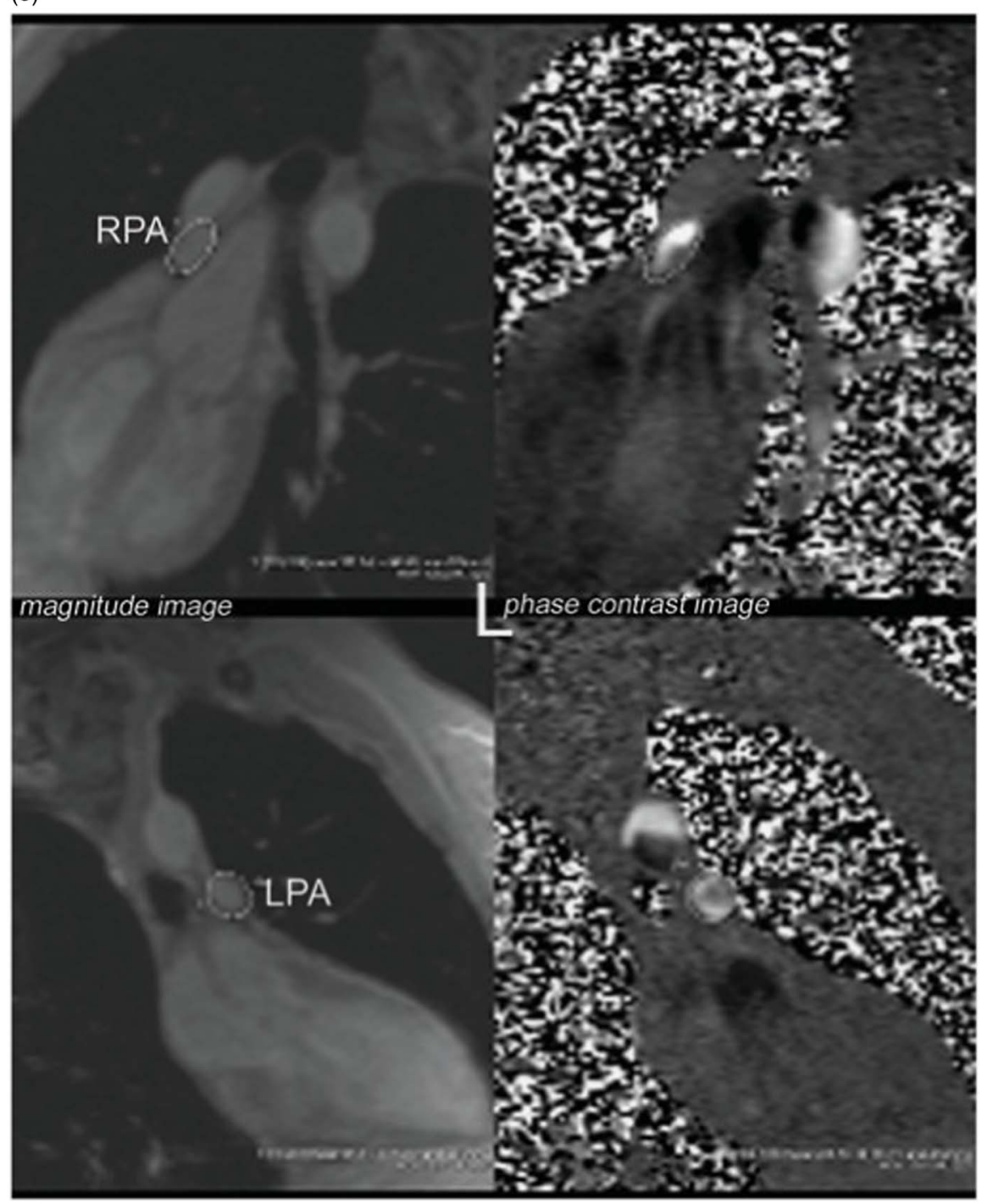

Figure 2 .

In a patient with transposition of the great arteries, who underwent the arterial switch operation with Lecomte manoeuvre, contrast-enhanced $M R$ angiography demonstrates well the relationship between the pulmonary arteries and the surrounding structures, in this case the ascending aorta (a). Flow measurements in the right pulmonary artery $(b)$ and in the left pulmonary artery (c) show a balanced lung perfusion with 50\% $150 \%$ flow to the right and to the left. AO, aorta; MPA, main pulmonary artery; LPA, left pulmonary artery; RPA, right pulmonary artery. 
Table 3. Flow measurements for the assessment of pulmonary (Qp) and systemic blood flows (Qs) in extraund intracardiac shunt lesions.

\begin{tabular}{lll}
\hline & Qp & Qs \\
\hline Intracardiac & PVs & SVC + IVC \\
shunt & RPA + LPA & SVC + DAO \\
& MPA & AAO \\
& Stroke volume RV & Stroke volume LV \\
Extracardiac & (ASD and PAPVC) & (ASD and PAPVC) \\
shunt & PVs & SVC + IVC \\
& RPA + LPA (AP window) & SVC + DAO \\
& Stroke volume LV & AAO \\
& (PDA, AP window and AP collaterals) & Stroke volume RV \\
\hline
\end{tabular}

AAO, ascending aorta; AP, aorto-pulmonary window or collaterals; DAO, descending aorta; IVC, inferior vena cava; LPA, left pulmonary artery; LV, left ventricle; MPA, main pulmonary artery; PDA, patent ductus arteriosus; PVs, pulmonary veins; RPA, right pulmonary artery; $\mathrm{RV}$, right ventricle; SVC, superior vena cava,

pulmonary artery stenosis, but also in pulmonary venous obstruction. ${ }^{68-70}$ Beside quantitative flow assessment, qualitative flow profiles may provide information about anomalous pulmonary resistance.

The presence of a stent in a pulmonary artery does not represent a contraindication for performing CMR imaging during follow-up assessment. Flow measurement can still be performed accurately, if PC cine images are acquired at a reasonable distance from the stent. Alternatively, pulmonary venous flow can be used as a surrogate for ipsilateral pulmonary arterial flow (Table 3).

\section{Expert consensus key points.}

(i) CMR combines a detailed visualization of the spatial alignment of the pulmonary arterial bifurcation and the side branches.

(ii) Through-plane flow measurements can accurately quantify differential lung perfusion in various conditions.

\section{The pulmonary veins}

CMR is considered the gold standard for assessing anomalous connection and stenosis of the pulmonary veins. CMR combines superb luminal anatomy, accurate quantification of blood flow patterns and volume and, importantly, information about the surrounding structures (Table 1)..$^{71,72}$

To obtain anatomical information about the vessel lumen in both pulmonary vein stenosis and anomalous connection, CE-MRA and/or 3D SSFP can be used (Fig 3). Alternatively to, or in conjunction with angiography, SSFP cine imaging along the vessel's long axis can provide useful information, particularly if dynamic external compression is suspected.

Velocity-encoded PC cine is a powerful tool in the characterization of pulmonary venous pathology. It is

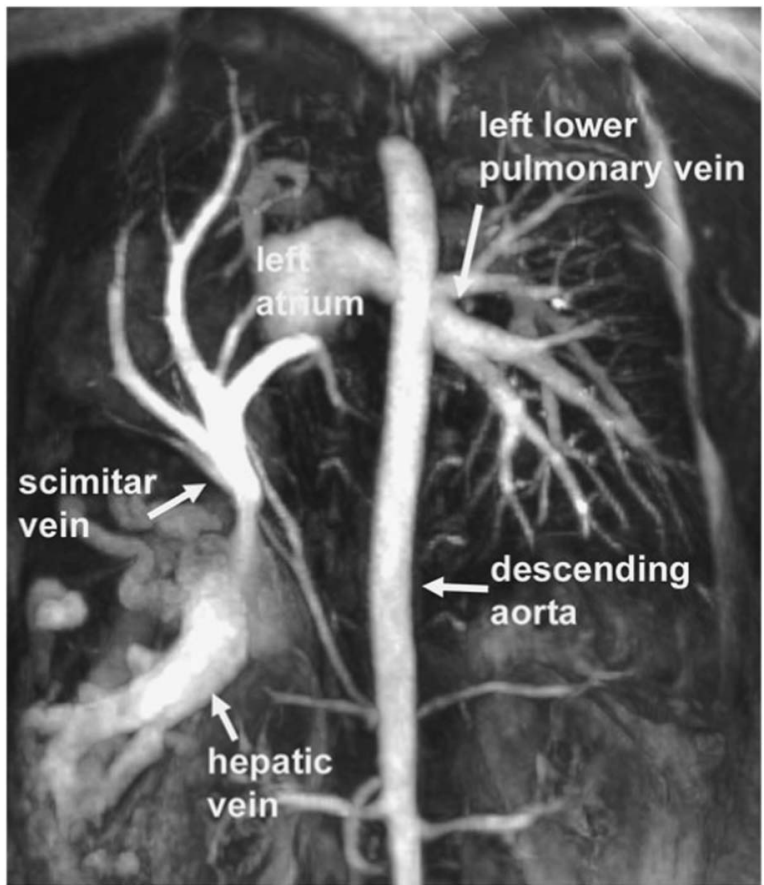

Figure 3 .

Maximum intensity projection reconstruction of $C E-M R A$ images in the coronal plane in a patient with Scimitar syndrome. All right-sided pulmonary veins drain via a common channel to a stenotic connection with the inferior vena cava (not opacified). The pulmonary venous blood from the right lung drains via collaterals to the dilated hepatic veins. The left-sided pulmonary veins drain normally to the left atrium (left upper pulmonary vein not shown).

used to measure right and left pulmonary arterial blood flow, to detect signs of pulmonary hypertension, and to unveil redistribution of blood flow away from affected areas of the lung. ${ }^{70}$

In anomalous pulmonary venous connection, it is important to detail the course and connection of each pulmonary vein, diagnose or rule out the presence of 
pulmonary venous obstruction, quantify the degree of left-to-right shunting (Qp/Qs), and describe associated lesions. ${ }^{69,73} \mathrm{~A}$ number of indicators during a CMR examination signal the presence of pulmonary vein stenosis. $^{71,74,75}$ The most obvious sign of obstruction is morphologically narrowing of the pulmonary venous lumen. This is best imaged by targeted SSFP cine imaging and CE-MRA. In some instances, veno-venous collaterals to unobstructed pulmonary venous channels and/or to systemic veins are present. Furthermore, higher than normal flow velocity distal to a suspected narrowing and loss of the normal phasic velocity flow profile are suggestive of a haemodynamically significant obstruction. ${ }^{75}$ Finally, as mentioned above, long-standing pulmonary venous narrowing leads to redistribution of pulmonary blood flow away from lung segments drained by the stenosed pulmonary vein, and results in an unbalanced lung perfusion, as easily detectable by velocity-encoded PC measurements in the branch pulmonary arteries.

\section{Expert consensus key points.}

(i) CMR is considered the gold standard for assessing anomalous connection and stenosis of the pulmonary veins.

(ii) Combined blood flow measurements in the pulmonary veins and in the pulmonary arteries allow understanding the complex flow redistribution occurring in the presence of pulmonary venous obstruction and aorto-pulmonary collateral flow.

\section{Shunt lesions}

The exact quantification of intracardiac shunts is part of the comprehensive haemodynamic evaluation in many patients with CHD and often a determinant factor for surgery. CMR is an established modality for the non-invasive assessment of shunt location, flow direction, and magnitude. ${ }^{76}$ Anatomical detection of lesions resulting in shunt flows is typically performed with cine acquisitions. When obtained perpendicular or parallel to the intracardiac shunt direction, they provide a valuable assessment of the defect location and size of intracardiac shunt lesions throughout the cardiac cycle. Extracardiac shunts, such as major aorto-pulmonary collaterals and anomalous pulmonary venous connection, are readily delineated by CE-MRA. ${ }^{71,77}$

Shunt calculation is one of the major strengths of CMR. As it provides accurate flow measurement in every desired vessel, CMR can overcome the wellknown limitations of the traditional Fick's method by oximetry as obtained with invasive techniques, or of Doppler echocardiography, which cannot quantify flow reliably. ${ }^{32,78}$

By using the velocity-encoded PC cine sequence, the ratio of pulmonary blood flow $(\mathrm{Qp})$ and systemic blood flow (Qs) can be accurately quantified and reflects the size of shunt.

Independently of the location of the shunt, Qp is always the sum of pulmonary venous flow and Qs is always the sum of inferior and superior venae cavae flows, measured close to the heart. ${ }^{79}$ Flow in the descending aorta may be used as a substitute for inferior vena cava flow and is technically easier to obtain. Depending on the anatomy, i.e. the location of the shunt, flows other than the pulmonary veins and the caval veins can be used as Qp and Qs, respectively (Table 3 ).

Another method to assess the magnitude of net shunts is to compare the selective cardiac output of the right with that of the left ventricle (Table 3). This method is commonly thought to be less accurate than velocity-encoded PC by many, owing to difficulties in accurately contouring the right ventricular (RV) endocardium including its trabeculations. Furthermore, this approach is inherently invalid in the presence of valvular regurgitation. For the purposes of 'internal validation', that is, to assess the accuracy of the flow measurements, Qp and Qs measured by different methods should be compared.

\section{Expert consensus key points.}

(i) CMR can be used for the anatomical detection of intracardiac and extracardiac shunts.

(ii) Shunt calculation is one of the major strengths of CMR.

(iii) Comparison of shunt quantifications using various measurements is recommended for internal validation' of the data and to increase accuracy.

\section{Tetralogy of Fallot}

TOF has become one of the main indications for performing CMR during follow-up of CHD after surgical repair. ${ }^{2}$ In young children, preoperatively, advanced imaging with CMR is only required in few selected cases with associated lesions such as situs anomalies, aortic arch anomalies, disconnected branch pulmonary arteries, and/or aorto-pulmonary collaterals. After initial surgical repair, typical residual findings during mid- and long-term follow-up include moderate to severe incompetence of the pulmonary valve, obstruction of the RV outflow tract, and/or branch pulmonary arteries. These findings cause chronic volume and/or pressure load of the right ventricle, with well-described and potentially lethal complications. ${ }^{80}$

Over the past two decades, CMR has been firmly established as the key imaging modality for serial follow-up in TOF patients. ${ }^{2} \mathrm{CMR}$ is the only technique that allows accurate quantification of pulmonary incompetence with measurement of regurgitation 
volumes and regurgitation fraction (both should be documented) by PC cine imaging (Table 1). ${ }^{81,82}$

The volume and systolic function of both ventricles are determined by acquiring a stacked 2D-cine SSFP covering the ventricles in short-axis or axial orientation $^{25,28}$ (Fig 4). This method has excellent reproducibility if performed in a standardized manner across institutions. ${ }^{31,83}$ Tricuspid valve regurgitation can be depicted using 2D SSFP, but is difficult to be correctly quantified due to the movements of the annulus plane during the cardiac cycle and to the usually co-existing pulmonary incompetence. Tailored 2D SSFP images through the RVOT, 3D SSFP, and/or CE-MRA give clear views of the anatomy of the RVOT and the pulmonary side branches. Additional functional information can be obtained by measuring the differential pulmonary perfusion and assessing the backflow separately in both pulmonary side branches. ${ }^{84,85}$

All this information is generally used in the clinical management of these patients and considered of particular importance in timing decisions regarding pulmonary valve replacement.

In this context, RV size and function are the main factors to be considered in addition to clinical symptoms and findings. Although there is no universal agreement on cut-off volume, an indexed end-diastolic $\mathrm{RV}$ volume of $160 \mathrm{ml} / \mathrm{m}^{2}$ and an end-systolic RV volume of $80 \mathrm{ml} / \mathrm{m}^{2}$ have been shown to predict normalization of $\mathrm{RV}$ size after pulmonary valve replacement. ${ }^{86}$ Proper selection of patients undergoing percutaneous pulmonary valve implantation requires accurate description of the geometry of the RVOT by CE-MRA or 3D SFFP and exclusion of anomalies of the coronary arteries by $3 \mathrm{D}$ SSFP.

The presence of myocardial scarring is detected by LGE of the myocardium, the extent of which has been found to be related to exercise intolerance, regional wall motion abnormalities, and propensity for arrhythmia.

Targeted 2D SSFP or CE-MRA may additionally detect dilatation of the ascending aorta, demonstrate arch sidedness (right aortic arch in $20 \%$ of patients with TOF), and exclude potential major aortopulmonary collateral arteries. ${ }^{87}$

\section{Expert consensus key points.}

(i) CMR is the key imaging modality for serial follow-up in TOF patients.

(ii) CMR enables the assessment of RV outflow tract, pulmonary bifurcation, and pulmonary arteries as well as quantification of RV volume and function and regurgitant blood flow in pulmonary regurgitation.

(iii) This information features prominently in surgical decision making around pulmonary valve replacement.

\section{Complex CHD}

Complex CHD frequently consists of a combination of situs anomalies, abnormal atrioventricular and/or ventriculo-arterial connections, and/or additional defects, including septal defects, ventricular looping anomalies, as well as malformations of the outflow tracts. In addition, malformations of the extracardiac thoracic vessels and tracheobronchial anomalies may be present.

Planning and performing CMR examinations in patients with complex CHD require thorough expertise in congenital malformations to avoid misinterpretation or incomplete results.

Dedicated CMR examinations provide a comprehensive picture of complex CHD, including anatomy and haemodynamics (Table 1). Three-dimensional reformatting algorithms may enhance surgical decision-making and planning of operative procedures. ${ }^{46}$

In complex CHD, views in axial, coronal, and sagittal orientations should always be at the beginning of every CMR exams to facilitate orientation within the thorax. Oblique imaging planes are tailored towards individual aspects of anatomy and for ventricular function and flow analyses. The abdomen should be covered in the localizer/scout images and by techniques, enabling the identification of vessel anatomy and size as well as anatomy of the upper abdominal organs ${ }^{88}$ (Fig 5).

Turbo spin-echo sequences are particularly useful for the evaluation of tracheo-bronchial anomalies and their relationship to the pulmonary vascular tree which provides important clues to the thoracic situs and for the detection of anomalies of the great arteries.

The use of CMR in complex CHD including heterotaxy syndrome has been validated in numerous studies ${ }^{89}$ and has been demonstrated to provide superior delineation of the abdominal situs, of pulmonary and systemic venous malformations, and of the relationship of the heart to abdominal and mediastinal structures compared with echocardiography and cardiac catheterization. ${ }^{88,90-92}$ Thus, CMR has been recently recognized as the first-line imaging modality for imaging complex CHD. ${ }^{2}$

\section{Expert consensus key points.}

(i) CMR is an important adjunct to echocardiography for imaging complex CHD in children and in adults.

(ii) CMR provides complete information about situs, segmental cardiac connections, additional intracardiac and extracardiac malformations, and accurate haemodynamic information.

\section{Single ventricles throughout staged palliation}

The palliative treatment strategy for functionally univentricular hearts may require between two and three or more procedures before achieving the 

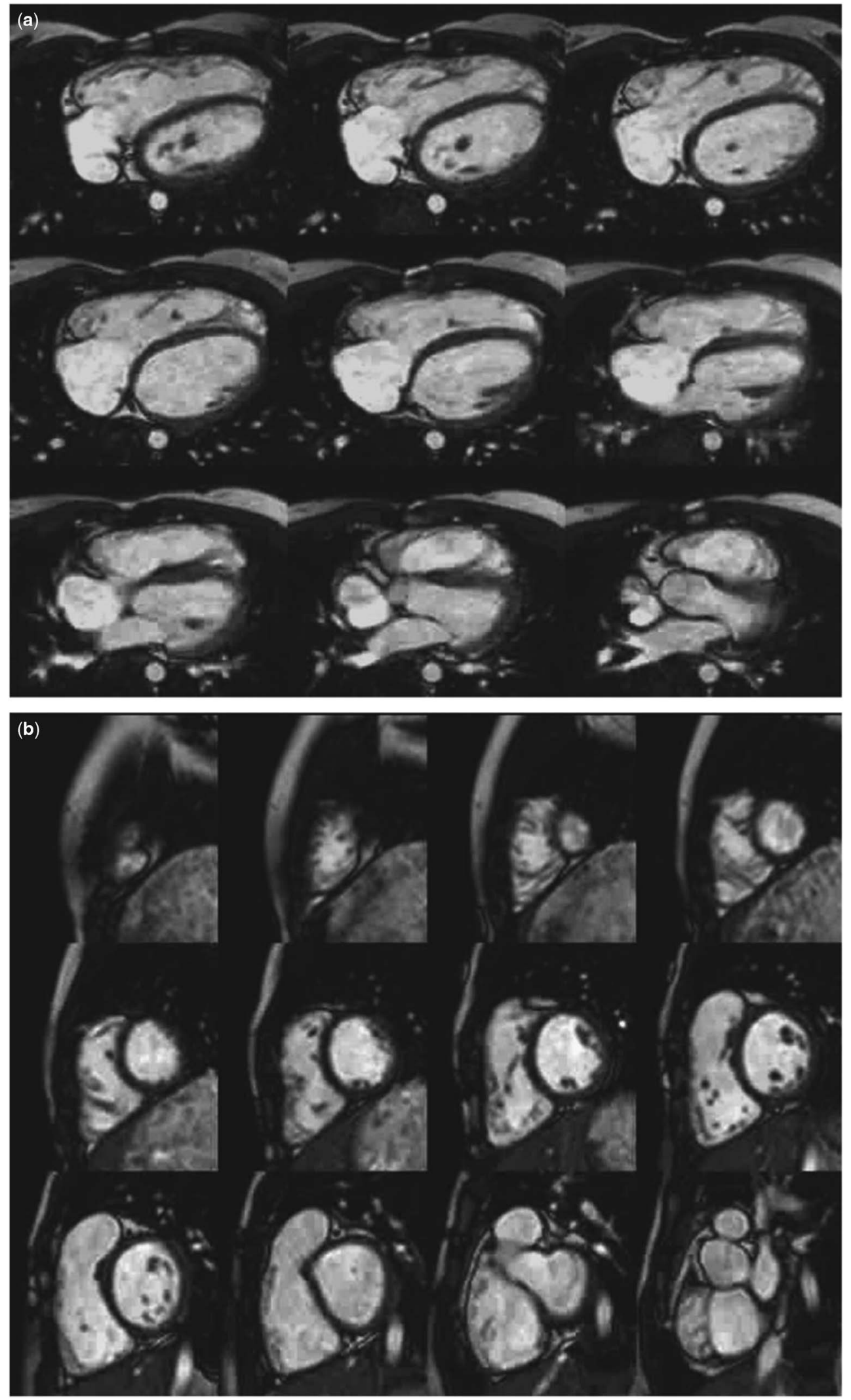

Figure 4.

$2 D$ SSFP of the ventricles in a patient with dilated RV after TOF repair as demonstrated in an axial stack $(\boldsymbol{a})$ and in a short-axis $\operatorname{stack}(b)$. 

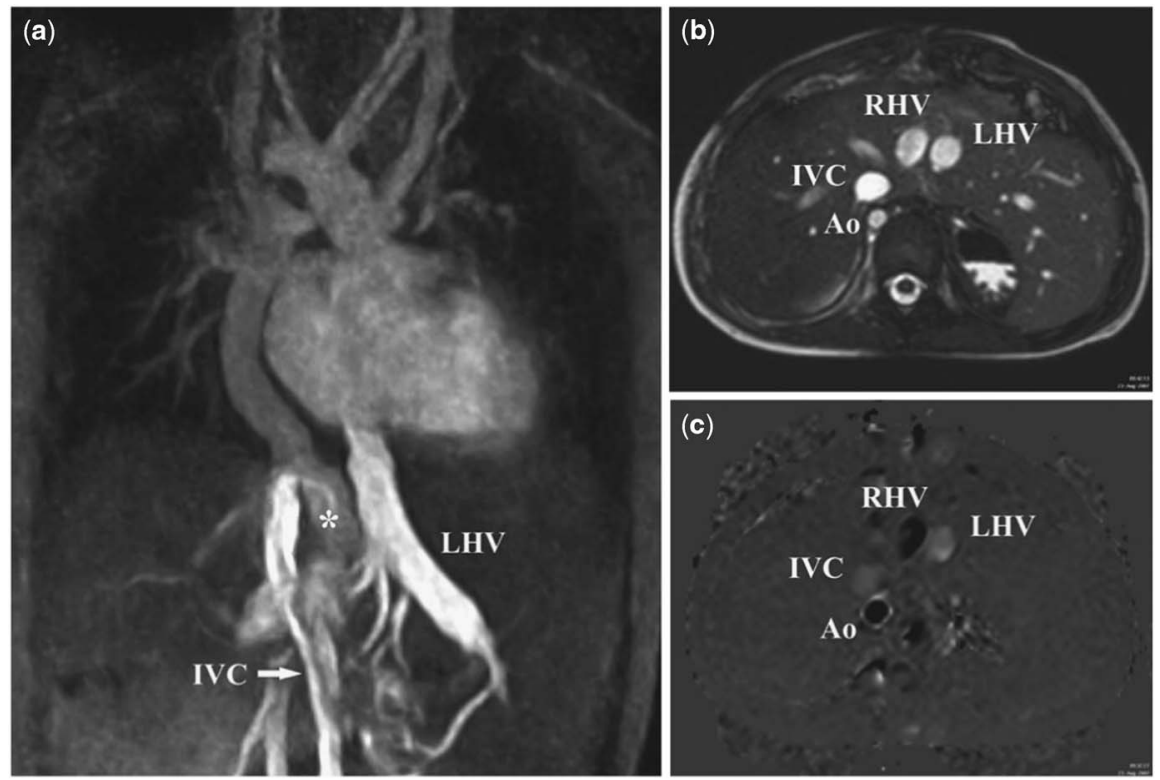

Figure 5 .

Four-year-old boy with right atrial isomerism, bilateral superior caval veins, univentricular atrioventricular connection to a solitary ventricle, pulmonary atresia, and right aortic arch developed severe bypoxaemia after Fontan completion due to a non-included left-sided hepatic vein. (a) Multiple intrabepatic collateral channels underscoring a right-to-left shunt from the right hepatic vein (RHV; asterisk) to the left hepatic vein $(L H V)$ and to the left-sided atrium. Contrast agent is applied via the left lower limb. (b) T2-weighted SSFP transverse plane "'3 cm below the diaphragm. Visceral heterotaxia. Both descending aorta (Ao) and inferior caval vein (IVC) are right-sided. RHV and LHV are arranged in nearly parallel fashion midline. (c) Flow measurement using velocity-encoded PC for quantification. Flow direction is encoded by optical density. Dark lumens indicate flow directed caudally. Reversely, bright lumens indicate flow directed cranially.

stage of the Fontan-type circulation. ${ }^{93,94}$ Strengths of CMR in the setting of single-ventricle circulations include the detailed assessment of potentially complex anatomy, particularly of the large vessels, functional imaging of the ventricles and large vessels throughout the stages, and assessment of flow, particularly of the pulmonary/Fontan circulation (Fig 6).

Prior to the creation of a partial cavopulmonary connection, imaging of the ascending aorta and aortic arch, of the pulmonary arteries, and of the systemic and pulmonary veins are mandatory. ${ }^{95}$ Ventricular size and function, valve function, and the subaortic outflow tract should be studied. A combination of 2D and 3D SSFP, black-blood, phase-contrast sequences and/or CE-MRA can be used for these purposes (Table 2) ${ }^{96}$ A combined protocol using echocardiography and CMR may result in less complications when compared with cardiac catheterizations and similar long-term outcomes in properly selected patients. $^{97}$ Imaging of an aorto- or ventriculopulmonary shunt can also be achieved with CMR by using 3D SSFP or CE-MRA. ${ }^{14}$

Before completion of a total cavopulmonary connection (TCPC), a similarly detailed work-up is required. In addition, the connection between the superior vena cava and the pulmonary arteries has to be visualized. The presence of significant aorto-pulmonary collateral vessels can be demonstrated by using CE-MRA. The difference of total pulmonary venous flow and the total branch pulmonary arterial flow allows quantifying the additional blood flow to the lungs due to aorto-pulmonary collaterals. $^{98}$ The use of only CMR for planning the TCPC stage is being discussed; ${ }^{19}$ however in most centres, haemodynamic studies before the completion of a Fontan-type circulation are still performed including cardiac catheterization (Table 1).

After completion of the Fontan circulation, CMR is recommended for serial follow-up of systolic and diastolic ventricular function, ventricular geometry, and serial quantification of valvular incompetence. ${ }^{94,95,99}$ Stress imaging can be used for testing ventricular contractile reserve in selected cases. ${ }^{36}$ Additional useful information provided by CMR during follow-up includes anatomy and function of the Fontan pathway, identifying obstructions, baffle leaks, thrombus formation, and collateral flow.

\section{Expert consensus key points.}

(i) In patients with single ventricles, CMR is recommended after Fontan completion for serial follow-up of ventricular function and anatomical assessment of the Fontan pathway. 
(a)

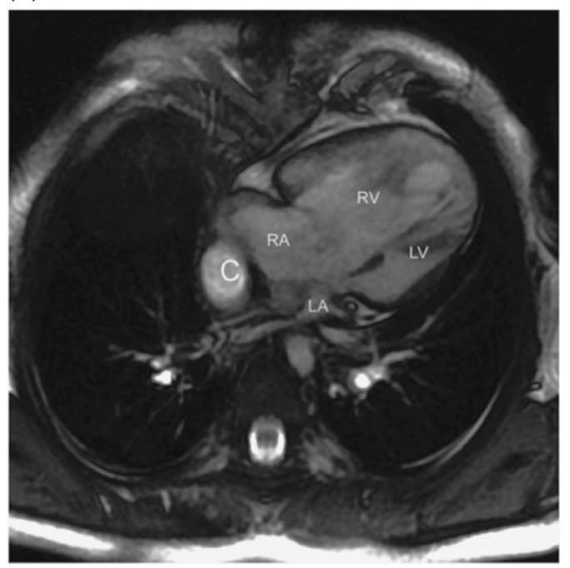

(c)

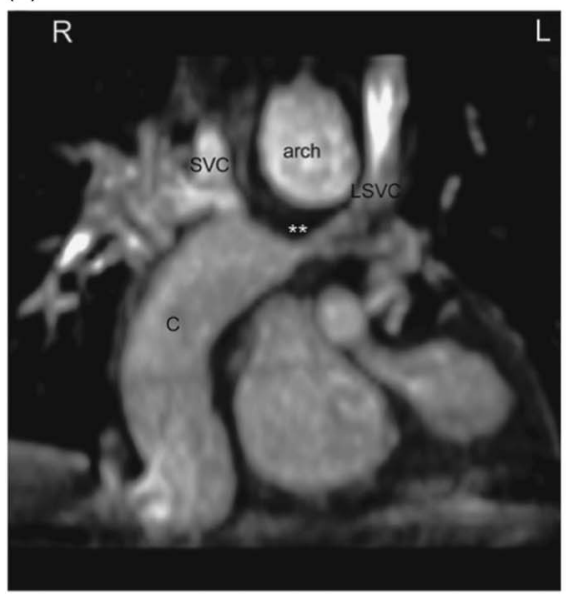

(b)

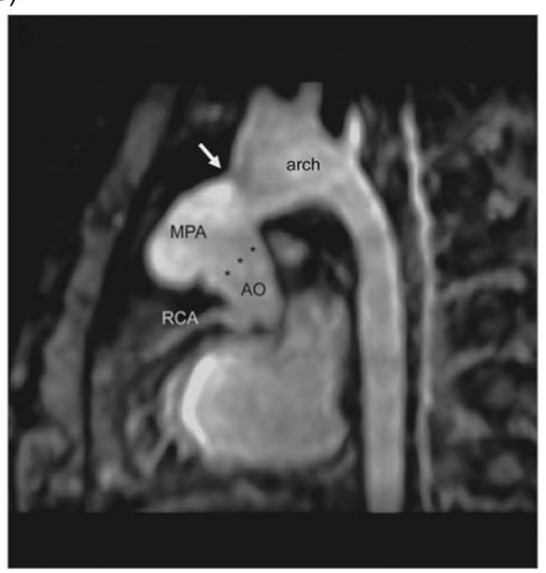

(d)

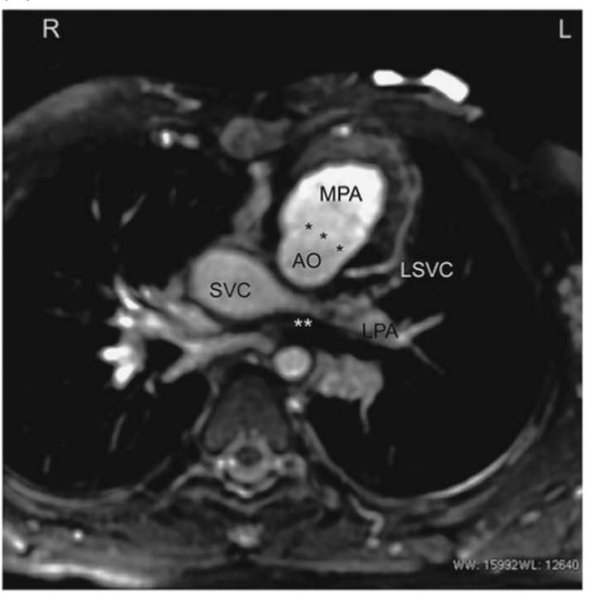

Figure 6.

Two-year-old girl with hypoplastic left heart syndrome (a) and status post-bilateral cavopulmonary anastomosis and Fontan completion. 3D SSFP images reconstructed with an MIP technique illustrate a patent Damus-Kaye-Stancel (DKS) anastomosis (***) with the origin of the right coronary artery (b); the segment between the right and left pulmonary artery (**) was reconstructed at time of Fontan completion, as it was subatretic due to external compression of the dilated neo-aortic root (DKS) and presents now with recurrent narrowing (c and $d$ ). AO, aorta; $C$, extracardiac Fontan conduit; MPA, main pulmonary artery; LA, left atrium; LV, left ventricle; LSVC, left superior vena cava; $R A$, right atrium; $R V$, right ventricle.

(ii) During staged palliation, CMR can be used to detect residual findings requiring additional interstage interventions.

\section{Cardiac tumours}

Paediatric cardiac tumours are rare and usually benign (75-90\%). Rhabdomyomas and fibromas are the most frequent cardiac tumours in children. Among malignant tumours, metastatic involvement from non-Hodgkin lymphoma, leukaemia, neuroblastoma, nephroblastoma, or sarcoma is much more common than primary cardiac sarcoma or lymphoma. ${ }^{100}$

CMR fulfils all the diagnostic goals of tumour imaging in one single examination (Table 1). ${ }^{101,102}$ Thus, a CMR examination should describe size and location of the tumour; evaluate any haemodynamic relevance, such as obstructions to inflow or outflow and impairment of myocardial and/or valvular function; describe the specific tissue properties of the mass, including signal/intensity ratio, infiltration of adjacent tissue, tissue appearance. Exact location in relation to the cardiac structures (endoluminal, floating, intramyocardial) should be included (Fig 7).

For a comprehensive evaluation of an intracardiac mass, the following imaging sequences and orientations are recommended: cine SSFP in an axial and oblique imaging plane across the tumour, $\mathrm{T}_{1}$-weighted TSE with and without fat suppression covering the tumour as well as the uninvolved ventricular myocardium, $\mathrm{T}_{2}$-weighted TSE, first-pass perfusion and $\mathrm{LGE}^{100}$ (Table 2). First-pass myocardial perfusion imaging may provide useful information about tumour vascularity. Moderate and strong enhancement is more indicative of malignant processes, whereas mild enhancement is found in up to $40-50 \%$ of benign tumours as well as in highly vascularized tumours. ${ }^{101,103}$ LGE does 

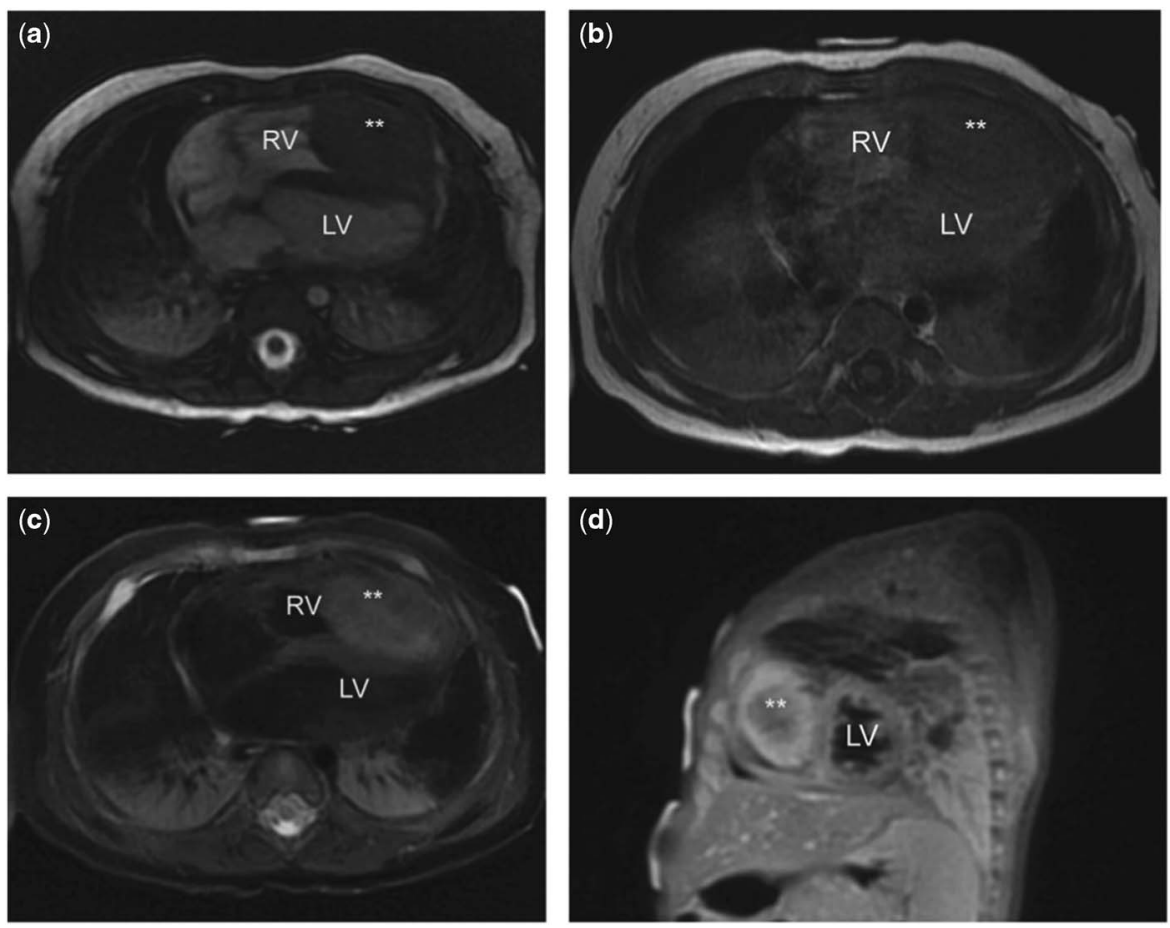

Figure 7.

Embryonic rhabdomyosarcoma (**) in the apex of the right ventricle in a 3-month-old boy. SSFP (a), T1-weighted (b), and T2-weighted images $(\boldsymbol{c})$ in an axial plane demonstrate different tissue characteristics in different sequences. Short-axis post-contrast images (d) show contrast medium enhancement particularly in the superficial tissue layers and less in the core of the tumour. LV, left ventricle; $R V$, right ventricle.
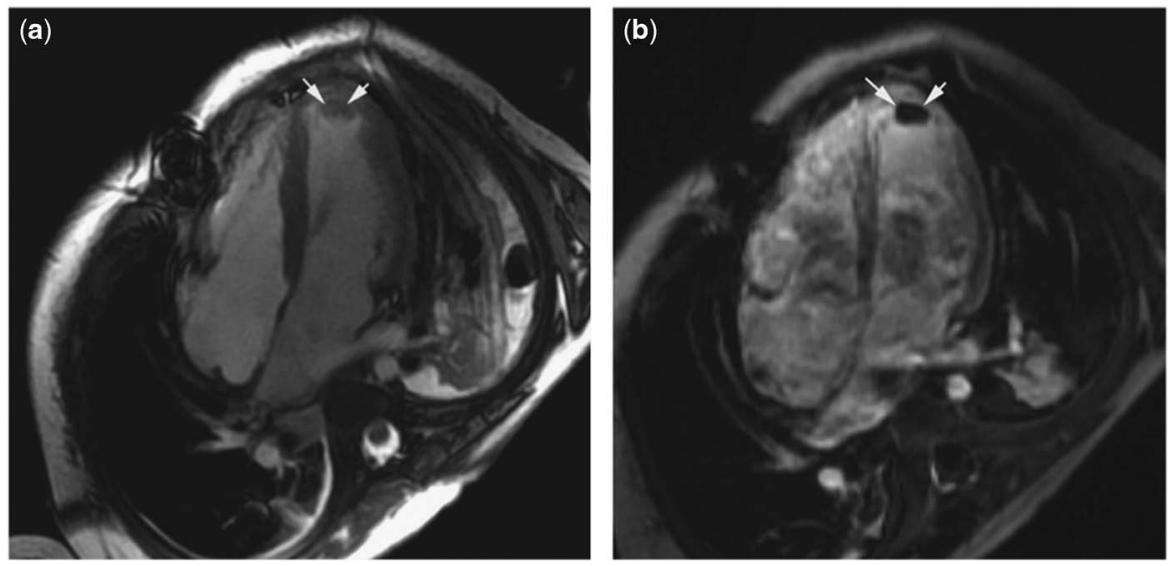

Figure 8.

Appearance of intracavity thrombus on $2 D \operatorname{SSFP}(\boldsymbol{a})$ and LGE images (b).

not predict malignancy, but is very helpful in tissue characterization. When an intracardiac thrombus is suspected, LGE imaging with a long inversion time (600 ms) is recommended (Fig 8). ${ }^{104}$

After having acquired all the different images, a correct diagnosis of the type of tumour can be derived by using the criteria proposed from a recent multicentre paediatric data collection. ${ }^{103}$ These criteria based on tissue characteristics shown by the different sequences used achieved a diagnostic accuracy of up to $97 \%$, with a single correct diagnosis in $55 \%$ and a correct differential diagnosis in $42 \%$, respectively. ${ }^{103}$ Diagnosis of malignancy can be at least suspected on the basis of tumour location, tissue inhomogeneity, and/or pericardial/pleural effusions with a sensitivity of 0.88 and specificity of $0.92 .^{105}$

Expert consensus key points.

(i) CMR is an important part of non-invasive tumour characterization by providing information on 

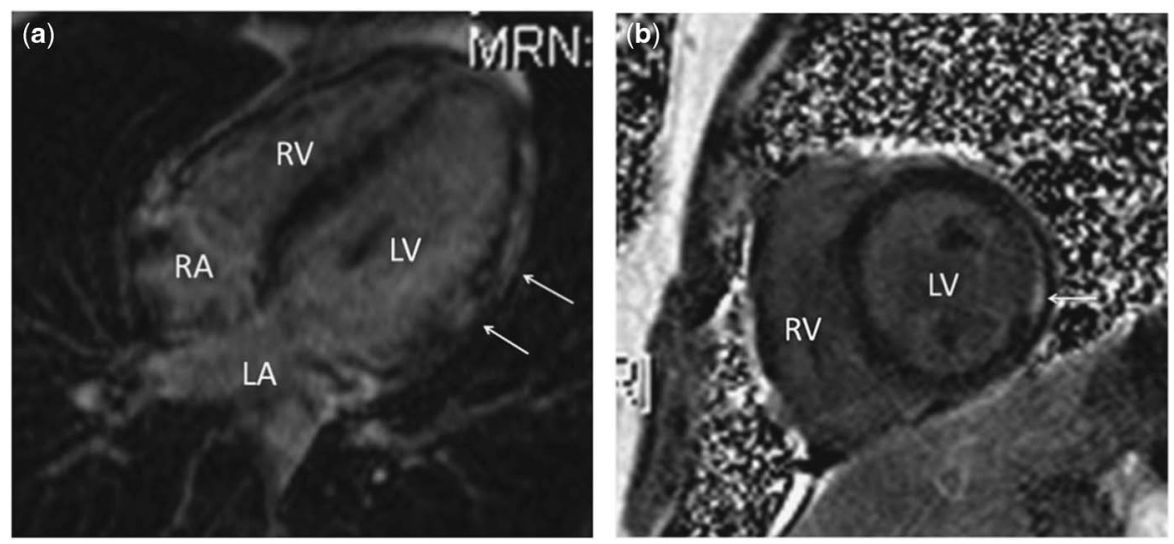

Figure 9.

Focal myocarditis in a 4-year-old child who presented with chest pain and elevated cardiac enzymes. LGE images in a horizontal long-axis view (a) and in short axis (b). Enhancement is found in the mid-wall of the lateral wall (arrows). 2D SSFP cine showed mild bypocontractility of the lateral wall, correspondingly.

size, location, haemodynamic relevance, relationship to the adjacent structures, infiltration, as well as tissue properties.

\section{Cardiomyopathies}

The two most common forms of paediatric cardiomyopathy are dilated cardiomyopathy (DCM; annual incidence 0.57 cases per 100,000) and hypertrophic cardiomyopathy (HCM; 0.47 per 100,000 persons). ${ }^{106}$

In addition to echocardiography, recognized as first-line imaging modality in children with cardiomyopathy, CMR provides noninvasive myocardial tissue characterization. In particular, CMR can detect the presence and extend of myocardial oedema, scarring and replacement fibrosis with high spatial resolution. In adults, pattern of fibrosis on LGE images may point towards the aetiology of the disease, and may influence decision-making and patient management. ${ }^{107,108}$

A wide range of abnormalities detectable with CMR have been related to the DCM phenotype, including coronary artery anomalies, idiopathic disease (majority of cases), or secondary causes, such as myocarditis or neuromuscular disorders. CMR is able to exclude anomalies of the origin and proximal course of the coronary arteries without the use of radiation and non-invasively. ${ }^{109}$ In the acute phase of myocarditis, CMR can be used to assess global ventricular function, detect regional wall motion abnormalities (2D SSFP cine imaging), early myocardial inflammatory changes $\left(\mathrm{T}_{2}\right.$-weighted imaging), as well as myocardial cell necrosis/fibrosis (LGE imaging) (Table 2). ${ }^{110}$ In chronic myocarditis, CMR can be used for monitoring biventricular function ${ }^{111}$ and demonstrate resolution of the inflammatory processes as well as late myocardial remodelling. ${ }^{107}$ The pattern of contrast distribution using LGE imaging is typically nodular, patchy, with a subepicardial and mid-wall myocardial distribution most commonly seen in the lateral and inferior walls of the left ventricle. In children, the extension of contrast is usually subepicardial, but may become transmural (Fig 9). ${ }^{110}$ The presence of pericardial effusion provides supportive evidence for myocarditis. CMR parameters significantly associated with poor outcomes in adult patients are: transmural myocardial late enhancement, global hypokinesia, LV dilation, and LV ejection fraction, 30\%. In neuromuscular disorders, CMR provides information about the degree of myocardial fibrosis, inflammation and impairment of myocardial contractility and relaxation. In patients with Duchenne muscular dystrophy, LGE allows identification of subjects at risk for progressive heart failure. ${ }^{112}$

In HCM, CMR provides accurate quantification of ventricular mass and function of both ventricles. The distribution of hypertrophy can be best delineated by acquiring images in several planes, and particularly apical hypertrophy can be detected more accurately than with echocardiography. The presence of fibrosis on LGE imaging is a potential risk factor for ventricular arrhythmias in adults ${ }^{113}$ and is observed more rarely in children. If HCM is related to an inborn error of metabolism (8\%), such as Fabry's or Pompe's diseases, CMR may be used to serially monitor the effects of enzyme replacement therapy. ${ }^{114}$

In left ventricular non-compaction, definition of criteria is challenging and controversial. LGE may not be present in children. ${ }^{115}$ Nevertheless, CMR has increased diagnostic accuracy compared with echocardiography, given that the anatomy of the cavity and trabeculae can be more clearly visualized. ${ }^{116}$

Assessment of myocardial iron load using $\mathrm{T}_{2}^{*}$ measurements is an established tool in the diagnosis 

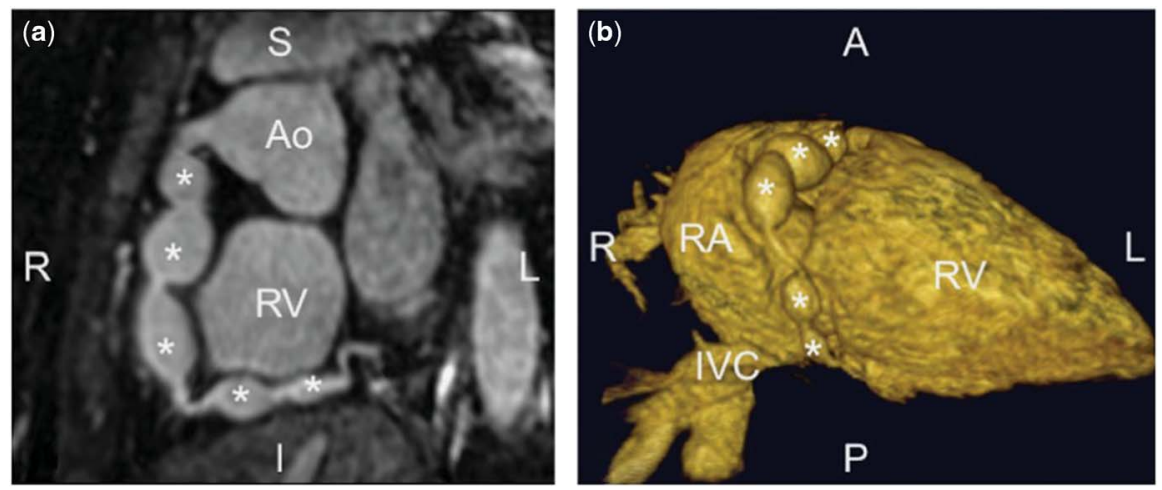

Figure 10.

3D SSFP images of a 7-year-old boy with Kawasaki disease. A curved multiplanar reformat $(a)$ and a volume-rendered $3 D$ reconstruction (b) demonstrate five aneurysms (asterisks) of the right coronary artery. AO, aorta; IVC, inferior vena cava; $R A$, right atrium; $R V$, right ventricle; $A$, anterior; $I$, inferior; $L$, left; $P$, posterior; $R$, right; $S$, superior.

of cardiac haemochromatosis in patients requiring repeated blood transfusions. The optimal timing for screening young patients by CMR is under debate, and depends on patient age and transfusion burden. Often, CMR can be postponed until 8 years of age so that anaesthesia is not required. A single measure of mid-septal $\mathrm{T}_{2}^{*}$ is sufficient and correlates well with the global $\mathrm{T}_{2}^{*}$.

CMR imaging of arrhythmogenic right ventricular cardiomyopathy (ARVC) in children is challenged by the evolving nature of the disease. ${ }^{118,119}$ Thus, repeated studies have been recommended. Morphological and regional wall motion abnormalities must be evaluated by careful analysis of SSFP cine images in different planes and orientations. CMR-based criteria for ARVC according to the revised Task Force Criteria include RV akinesia/dyskinesia, but only when combined with RV dilatation and/or reduced ejection fraction. ${ }^{120}$ Imaging of fatty infiltration or LGE appears to be of low yield in children. ${ }^{119}$

\section{Expert consensus key points.}

(i) At time of diagnosis and during follow-up of patients with cardiomyopathies, the strengths of CMR are specific tissue characterization and accurate quantification of ventricular volume and function.

(ii) In dilatative cardiomyopathy, CMR can aid in determining the aetiology of the disease.

(iii) In HCM, CMR is used for exact quantification of myocardial mass, delineation of the distribution of hypertrophy, as well as for detection and quantification of myocardial fibrosis.

\section{Coronary arteries/perfusion}

In children, imaging of the coronary arteries (CA) and evaluation of myocardial perfusion with first-pass myocardial imaging as well as the presence of myocardial scars are indicated in suspected congenital anomalies of the CA, CA fistulas, after surgery for CHD involving CA transfer, before percutaneous pulmonary valve replacement with a valve veering stent, and in patients with vasculitis (e.g. Kawasaki, Takayasu arteritis, or after heart transplantation). ${ }^{33,121,122}$ Even though the capability to provide all this combined information makes CMR a unique modality, cardiac catheterization currently remains the gold standard for CA imaging in children (Table 1). ECG-gated multidetector row CT is an established non-invasive alternative for $\mathrm{CA}$ assessment because it is easy to use, generally available and exploits fast acquisition times compared with CMR in adults. However, important limitations in children remain radiation exposure and fast heart rate. ${ }^{123}$

Magnetic resonance coronary artery (MRCA) imaging of the proximal and mid regions of the major epicardial CA by using 3D SSFP can be performed in infants and children ${ }^{19,24,124}$ (Fig 10). As the patients growth and heart rate decreases, image quality increases. This technique can be used to detect an anomalous origin and proximal course of the CA. ${ }^{109}$ Although the ability to asses CA in children with Kawasaki disease and to evaluate the vessel wall of the CA has been reported, ${ }^{122}$ the validity of MRCA for reliable detection of CA stenoses is unclear.

Assessment of myocardial perfusion with first-pass myocardial imaging has been validated in the adult population and has been demonstrated to have a diagnostic performance superior to SPECT. ${ }^{125,126}$ The clinical experience in children is limited, but good sensitivity and specificity have been demonstrated in comparison with X-ray coronary angiography. ${ }^{33,34}$ Performing first-pass imaging in children (see basic sequences) requires adapting the acquisition parameters to the higher heart rate and the small dimensions of the heart. Age and body size 
are still limiting factors, and infants below the age of 1 year are still considered suboptimal candidates. Nevertheless, myocardial perfusion imaging in older children may provide crucial additional dynamic information in addition to static conventional coronary angiography performed by catheterization. Moreover, myocardial perfusion imaging can be used for selecting patients, who really necessitate invasive coronary angiography.

LGE imaging provides information regarding the viability of myocardial tissue. Areas of late enhancement correlate well with areas of fibrosis (scars). ${ }^{127}$ Frequent paediatric indications for LGE imaging include myocardial infarctions after surgery, CA thrombosis in Kawasaki disease, follow-up of different CHD, HCM, and myocarditis (Fig 9). ${ }^{34,128,129}$

\section{Expert consensus key points.}

(i) In children, CMR can be used for imaging of the proximal segments of the coronary arteries and for assessment of myocardial perfusion.

(ii) High heart rate and small size remain limiting factors in young children.

\section{Conclusions}

CMR has become a widely accepted technique for a large number of different indications in children with heart disease. Specific cardiac, paediatric as well as imaging expertise is required and should be available in centres applying CMR in these patients, as the imaging approach requires careful tailoring to the specific question and individual patient.

\section{Funding}

S.S. was supported by the Competence Network for Congenital Heart Defects funded by the German Federal Ministry of Education and Research (BMBF) under grant numbers FKZ 01G10210 and 01Gi0601.

\section{Conflict of interest}

C.B.D. is consultant for Circle Cardiovascular Imaging Inc., Calgary, Canada.

\section{References}

1. Nieminen HP, Jokinen EV, Sairanen HI. Causes of late deaths after pediatric cardiac surgery: a population-based study. J Am Coll Cardiol 2007; 50: 1263-1271.

2. Kilner PJ, Geva T, Kaemmerer H, Trindade PT, Schwitter J, Webb GD. Recommendations for cardiovascular magnetic resonance in adults with congenital heart disease from the respective working groups of the European Society of Cardiology. Eur Heart J 2010; 31: 794-805.
3. Fratz S, Chung T, Greil G, et al. Guidelines and protocols for cardiovascular magnetic resonance in children and adults with congenital heart disease: SCMR expert consensus group on congenital heart disease. J Cardiovasc Magn Reson 2013; 15: 51.

4. Fratz S, Hess J, Schuhbaeck A, et al. Routine clinical cardiovascular magnetic resonance in paediatric and adult congenital heart disease: patients, protocols, questions asked and contributions made. J Cardiovasc Magn Reson 2008; 10: 46.

5. Tsai-Goodman B, Geva T, Odegard KC, Sena LM, Powell AJ. Clinical role, accuracy, and technical aspects of cardiovascular magnetic resonance imaging in infants. Am J Cardiol 2004; 94: 69-74.

6. Helbing WA, Mertens L, Sieverding L. Recommendations from the Association for European Paediatric Cardiology for training in congenital cardiovascular magnetic resonance imaging. Cardiol Young 2006; 16: 410-412.

7. Plein S, Schulz-Menger J, Almeida A, et al. Training and accreditation in cardiovascular magnetic resonance in Europe: a position statement of the working group on cardiovascular magnetic resonance of the European Society of Cardiology. Eur Heart J 2011; 32: 793-798.

8. Finn JP, Nael K, Deshpande V, Ratib O, Laub G. Cardiac MR imaging: state of the technology. Radiology 2006; 241: 338-354.

9. Garg R, Powell AJ, Sena L, Marshall AC, Geva T. Effects of metallic implants on magnetic resonance imaging evaluation of Fontan palliation. Am J Cardiol 2005; 95: 688-691.

10. Holmqvist C, Larsson EM, Stahlberg F, Laurin S. Contrastenhanced thoracic 3D-MR angiography in infants and children. Acta Radiol 2001; 42: 50-58.

11. Meng H, Grosse-Wortmann L. Gadolinium in pediatric cardiovascular magnetic resonance: what we know and how we practice. J Cardiovasc Magn Reson 2012; 14: 56.

12. Masui T, Katayama M, Kobayashi S, et al. Gadolinium-enhanced MR angiography in the evaluation of congenital cardiovascular disease pre and postoperative states in infants and children. J Magn Reson Imaging 2000; 12: 1034-1042.

13. Valsangiacomo Buechel E, DiBernardo S, Bauersfeld U, Berger F. Contrastenhanced magnetic resonance angiography of the great arteries in patients with congenital heart disease: an accurate tool for planning catheter-guided interventions. Int J Cardiovasc Imaging 2005; 21: 313-322.

14. Kellenberger CJ, Yoo S-J, Buechel ERV. Cardiovascular MR imaging in neonates and infants with congenital heart disease. Radiographics 2007; 27: 5-18.

15. Macgowan CK, Al-Kwifi O, Varodayan F, Yoo SJ, Wright GA, Kellenberger CJ. Optimization of 3D contrast-enhanced pulmonary magnetic resonance angiography in pediatric patients with congenital heart disease. Magn Reson Med 2005; 54: 207-212.

16. Geva T, Greil GF, Marshall AC, Landzberg M, Powell AJ. Gadolinium-enhanced 3-dimensional magnetic resonance angiography of pulmonary blood supply in patients with complex pulmonary stenosis or atresia: comparison with $\mathrm{X}$-ray angiography. Circulation 2002; 106: 473-478.

17. Greil GF, Powell AJ, Gildein HP, Geva T. Gadolinium-enhanced three-dimensional magnetic resonance angiography of pulmonary and systemic venous anomalies. J Am Coll Cardiol 2002; 39: 335-341.

18. Goyen M, Laub G, Ladd ME, et al. Dynamic 3D MR angiography of the pulmonary arteries in under four seconds. J Magn Reson Imaging 2001; 13: 372-377.

19. Piccini D, Monney P, Sierro C, et al. Respiratory self-navigated postcontrast whole-heart coronary MR angiography: initial experience in patients. Radiology 2014; 270: 378-386.

20. Sorensen TS, Korperich H, Greil GF, et al. Operator independent isotropic three-dimensional magnetic resonance imaging for morphology in congenital heart disease: a validation study. Circulation 2004; 110: 163-169. 
21. Razavi RS, Hill DL, Muthurangu V, et al. Three-dimensional magnetic resonance imaging of congenital cardiac anomalies. Cardiol Young 2003; 13: 461-465.

22. Fenchel M, Greil GF, Martirosian P, et al. Three-dimensional morphological magnetic resonance imaging in infants and children with congenital heart disease. Pediatr Radiol 2006; 36: $1265-1272$.

23. Su JT, Chung T, Muthupillai R, et al. Usefulness of real-time navigator magnetic resonance imaging for evaluating coronary artery origins in pediatric patients. Am J Cardiol 2005; 95: 679-682.

24. Tangcharoen T, Bell A, Hegde S, et al. Detection of coronary artery anomalies in infants and young children with congenital heart disease by using MR imaging. Radiology 2011; 259: 240-247.

25. Buechel EV, Kaiser T, Jackson C, Schmitz A, Kellenberger CJ. Normal right and left ventricular volumes and myocardial mass in children measured by steady state free precession cardiovascular magnetic resonance. J Cardiovasc Magn Reson 2009; 11: 19.

26. Sarikouch S, Peters B, Gutberlet M, et al. Sex-specific pediatric percentiles for ventricular size and mass as reference values for cardiac MRI: assessment by steady-state free-precession and phase contrast MRI flow. Circ Cardiovasc Imaging 2010; 3: 65-76.

27. Robbers-Visser D, Boersma E, Helbing WA. Normal biventricular function, volumes, and mass in children aged 8 to 17 years. J Magn Reson Imaging 2009; 29: 552-559.

28. Fratz S, Schuhbaeck A, Buchner C, et al. Comparison of accuracy of axial slices versus short-axis slices for measuring ventricular volumes by cardiac magnetic resonance in patients with corrected tetralogy of Fallot. Am J Cardiol 2009; 103: 1764-1769.

29. Sarikouch S, Koerperich H, Boethig D, et al. Reference values for atrial size and function in children and young adults by cardiac MR: a study of the German competence network congenital heart defects. J Magn Reson Imaging 2011; 33: 1028-1039.

30. Mooij CF, de Wit CJ, Graham DA, Powell AJ, Geva T. Reproducibility of MRI measurements of right ventricular size and function in patients with normal and dilated ventricles. J Magn Reson Imaging 2008; 28: 67-73.

31. Beerbaum P, Barth P, Kropf S, et al. Cardiac function by MRI in congenital heart disease: impact of consensus training on interinstitutional variance. J Magn Reson Imaging 2009; 30: 956-966.

32. Powell AJ, Maier SE, Chung T, Geva T. Phase-velocity cine magnetic resonance imaging measurement of pulsatile blood flow in children and young adults: in vitro and in vivo validation. Pediatr Cardiol 2000; 21: 104-110.

33. Buechel ER, Balmer C, Bauersfeld U, Kellenberger CJ, Schwitter J. Feasibility of perfusion cardiovascular magnetic resonance in paediatric patients. J Cardiovasc Magn Reson 2009; 11: 51.

34. Taylor A, Dymarkowski S, Hamaekers P, et al. Magnetic resonance coronary angiography and late-enhancement myocardial imaging in children with arterial switch operation for transposition of the great arteries. Radiology 2005; 234: 542-547.

35. Chiribiri A, Bettencourt N, Nagel E. Cardiac magnetic resonance stress testing: results and prognosis. Curr Cardiol Rep 2009; 11: 54-60.

36. Robbers-Visser D, Jan Ten Harkel D, Kapusta L, et al. Usefulness of cardiac magnetic resonance imaging combined with low-dose dobutamine stress to detect an abnormal ventricular stress response in children and young adults after Fontan operation at young age. Am J Cardiol 2008; 101: 1657-1662.

37. Harris MA, Johnson TR, Weinberg PM, Fogel MA. Delayedenhancement cardiovascular magnetic resonance identifies fibrous tissue in children after surgery for congenital heart disease. J Thorac Cardiovasc Surg 2007; 133: 676-681.

38. Bergersen L, Gauvreau K, Lock JE, Jenkins KJ. A risk adjusted method for comparing adverse outcomes among practitioners in pediatric and congenital cardiac catheterization. Congen Heart Dis 2008; 3: 230-240.
39. Mehta R, Lee KJ, Chaturvedi R, Benson L. Complications of pediatric cardiac catheterization: a review in the current era. Catheter Cardiovasc Interven 2008; 72: 278-285.

40. Bacher K, Bogaert E, Lapere R, De Wolf D, Thierens H. Patientspecific dose and radiation risk estimation in pediatric cardiac catheterization. Circulation 2005; 111: 83-89.

41. Beekman RP, Hoorntje TM, Beek FJA, Kuijten RH. Sedation for children undergoing magnetic resonance imaging: efficacy and safety of rectal thiopental. Eur J Pediatr 1996; 155: 820-822.

42. Odegard KC, DiNardo JA, Tsai-Goodman B, Powell AJ, Geva T, Laussen PC. Anaesthesia considerations for cardiac MRI in infants and small children. Pediatr Anesth 2004; 14: 471-476.

43. Dorfman AL, Odegard KC, Powell AJ, Laussen PC, Geva T. Risk factors for adverse events during cardiovascular magnetic resonance in congenital heart disease. J Cardiovasc Magn Reson 2007; 9: 793-798.

44. Sarikouch S, Schaeffler R, Körperich H, Dongas A, Haas N, Beerbaum P. Cardiovascular magnetic resonance imaging for intensive care infants: safe and effective? Pediatr Cardiol 2009; 30: $146-152$.

45. Committee on D. Guidelines for monitoring and management of pediatric patients during and after sedation for diagnostic and therapeutic procedures. Pediatrics 1992; 89: 1110-1115.

46. Picano E, Vañó E, Rehani MM, et al. The appropriate and justified use of medical radiation in cardiovascular imaging: a position document of the ESC associations of cardiovascular imaging, percutaneous cardiovascular interventions and electrophysiology. Eur Heart J 2014; 35: 665-672.

47. Knuuti J, Bengel F, Bax JJ, et al. Risks and benefits of cardiac imaging: an analysis of risks related to imaging for coronary artery disease. Eur Heart J 2014; 35: 633-638.

48. Shellock FG, Spinazzi A. MRI safety update 2008: part 2, screening patients for MRI. AJR Am J Roentgenol 2008; 191: 1140-1149.

49. Chaljub G, Kramer LA, Johnson RFI, Johnson RFJ, Singh H, Crow WN. Projectile cylinder accidents resulting from the presence of ferromagnetic nitrous oxide or oxygen tanks in the MR suite. AJR Am J Roentgenol 2001; 177: 27-30.

50. Food and Drug Administration, Center for Devices and Radiological Health. U.S. Department of Health and Human Services, Criteria for Significant Risk Investigations of Magnetic Resonance Diagnostic Devices. Food and Drug Administration, Hampton, Virginia USA, 2003.

51. Levine GN, Gomes AS, Arai AE, et al. American Heart Association Committee on Diagnostic and Interventional Cardiac Catheterization; American Heart Association Council on Clinical Cardiology; American Heart Association Council on Cardiovascular Radiology and Intervention. Safety of magnetic resonance imaging in patients with cardiovascular devices: an American Heart Association scientific statement from the Committee on Diagnostic and Interventional Cardiac Catheterization, Council on Clinical Cardiology, and the Council on Cardiovascular Radiology and Intervention: endorsed by the American College of Cardiology Foundation, the North American Society for Cardiac Imaging, and the Society for Cardiovascular Magnetic Resonance. Circulation 2007; 116: 2878-2891.

52. Bhachu DS, Kanal E. Implantable pulse generators (pacemakers) and electrodes: safety in the magnetic resonance imaging scanner environment. J Magn Reson Imaging 2000; 12: 201-204.

53. Rod Gimbel J, Bello D, Schmitt M, et al. Randomized trial of pacemaker and lead system for safe scanning at 1.5 Tesla. Heart Rhythm 2013; 10: 685-691.

54. Shellock FG, Spinazzi A. MRI safety update 2008: part 1, MRI contrast agents and nephrogenic systemic fibrosis. AJR Am J Roentgenol 2008; 191: 1129-1139.

55. Leiner T, Kucharczyk W. NSF prevention in clinical practice: summary of recommendations and guidelines in the United States, Canada, and Europe. J Magn Reson Imaging 2009; 30: $1357-1363$ 
56. Thomsen HS. Nephrogenic systemic fibrosis: history and epidemiology. Radiol Clin North Am 2009; 47: 827-831.

57. Eichhorn J, Fink C, Delorme S, Ulmer H. Rings, slings and other vascular abnormalities. Ultrafast computed tomography and magnetic resonance angiography in pediatric cardiology. Z Kardiol 2004; 93: 201-208.

58. Eichhorn JG, Krissak R, Rudiger HJ, et al. Compliance of the normal-sized aorta in adolescents with Marfan syndrome: comparison of MR measurements of aortic distensibility and pulse wave velocity. Rofo 2007; 179: 841-846.

59. Kellenberger C. Aortic arch malformations. Pediatr Radiol 2010; 40: 876-884.

60. Greil GF, Kramer U, Dammann F, et al. Diagnosis of vascular rings and slings using an interleaved 3D double-slab FISP MR angiography technique. Pediatr Radiol 2005; 35: 396-401.

61. Kaiser T, Kellenberger CJ, Albisetti M, Bergsträsser E, Valsangiacomo Buechel ER. Normal values for aortic diameters in children and adolescents - assessment in vivo by contrast-enhanced CMR-angiography. J Cardiovasc Magn Reson 2008; 10: 56.

62. Konen E, Merchant N, Provost Y, McLaughlin PR, Crossin J, Paul NS. Coarctation of the aorta before and after correction: the role of cardiovascular MRI. AJR Am J Roentgenol 2004; 182: 1333-1339.

63. Riquelme C, Laissy JP, Menegazzo D, et al. MR imaging of coarctation of the aorta and its postoperative complications in adults: assessment with spin-echo and cine-MR imaging. Magn Reson Imaging 1999; 17: 37-46.

64. Prince MR, Narasimham DL, Jacoby WT, et al. Three-dimensional gadolinium-enhanced MR angiography of the thoracic aorta. AJR Am J Roentgenol 1996; 166: 1387-1397.

65. Oshinski JN, Parks WJ, Markou CP, et al. Improved measurement of pressure gradients in aortic coarctation by magnetic resonance imaging. J Am Coll Cardiol 1996; 28: 1818-1826.

66. Caputo GR, Kondo C, Masui T, et al. Right and left lung perfusion: in vitro and in vivo validation with oblique-angle, velocity-encoded cine MR imaging. Radiology 1991; 180: 693-698.

67. Knobel Z, Kellenberger CJ, Kaiser T, Albisetti M, Bergstrasser E, Buechel ER. Geometry and dimensions of the pulmonary artery bifurcation in children and adolescents: assessment in vivo by contrast-enhanced MR-angiography. Int J Cardiovasc Imaging 2011; 27: 385-396.

68. Roman KS, Kellenberger CJ, Farooq S, MacGowan CK, Gilday DL, Yoo SJ. Comparative imaging of differential pulmonary blood flow in patients with congenital heart disease: magnetic resonance imaging versus lung perfusion scintigraphy. Pediatr Radiol 2005; 35: 295-301.

69. Roman KS, Kellenberger CJ, Macgowan CK, et al. How is pulmonary arterial blood flow affected by pulmonary venous obstruction in children? A phase-contrast magnetic resonance study. Pediatr Radiol 2005; 35: 580-586.

70. Kellenberger CJ, Macgowan CK, Roman KS, et al. Hemodynamic evaluation of the peripheral pulmonary circulation by cine phasecontrast magnetic resonance imaging. J Magn Reson Imaging 2005; 22: 780-787.

71. Valsangiacomo ER, Hornberger LK, Barrea C, Smallhorn JF, Yoo SJ. Partial and total anomalous pulmonary venous connection in the fetus: two-dimensional and Doppler echocardiographic findings. Ultrasound Obstet Gynecol 2003; 22: 257-263.

72. Grosse-Wortmann L, Al-Otay A, Goo HW, et al. Anatomical and functional evaluation of pulmonary veins in children by magnetic resonance imaging. J Am Coll Cardiol 2007; 49: 993-1002.

73. Riesenkampff EM, Schmitt B, Schnackenburg B, et al. Partial anomalous pulmonary venous drainage in young pediatric patients: the role of magnetic resonance imaging. Pediatr Cardiol 2009; 30: 458-464.

74. Goo HW, Al-Otay A, Grosse-Wortmann L, Wu S, Macgowan CK, Yoo SJ. Phase contrast magnetic resonance quantification of normal pulmonary venous return. J Magn Reson Imaging 2009; 29: 588-594.

75. Valsangiacomo ER, Barrea C, Macgowan CK, Smallhorn JF, Coles JG, Yoo SJ. Phase contrast MR assessment of pulmonary venous blood flow in children with surgically repaired pulmonary veins. Pediatr Radiol 2003; 33: 607-613.

76. Beerbaum P, Korperich H, Barth P, Esdorn H, Gieseke J, Meyer H. Noninvasive quantification of left-to-right shunt in pediatric patients: phase-contrast cine magnetic resonance imaging compared with invasive oximetry. Circulation 2001; 103: 2476-2482.

77. Valente A, Sena L, Powell A, Del Nido P, Geva T. Cardiac magnetic resonance imaging evaluation of sinus venosus defects: comparison to surgical findings. Pediatr Cardiol 2007; 28: 51-56.

78. Powell AJ, Tsai-Goodman B, Prakash A, Greil GF, Geva T. Comparison between phase-velocity cine magnetic resonance imaging and invasive oximetry for quantification of atrial shunts. Am J Cardiol 2003; 91: 1523-1525.

79. Grosse-Wortmann LL, Windram J, Yoo SJ. Magnetic resonance imaging and computed tomography. In Baker E, Anderson R, Penny D, Redington A, Rigby M, Wernowsky G (eds), Paediatric Cardiology, 2nd ed, Philadelphia, Churchill Livingstone Elsevier; 2009: p363-p378.

80. Gatzoulis MA, Balaji S, Webber SA, et al. Risk factors for arrhythmia and sudden cardiac death late after repair of tetralogy of Fallot: a multicentre study. Lancet 2000; 356: 975-981.

81. Rebergen SA, Chin JG, Ottenkamp J, van der Wall EE, de Roos A. Pulmonary regurgitation in the late postoperative follow-up of tetralogy of Fallot. Volumetric quantitation by nuclear magnetic resonance velocity mapping. Circulation 1993; 88 (5 Pt 1): 2257-2266.

82. Wald RM, Redington AN, Pereira A, et al. Refining the assessment of pulmonary regurgitation in adults after tetralogy of Fallot repair: should we be measuring regurgitant fraction or regurgitant volume? Eur Heart J 2009; 30: 356-361.

83. Sarikouch S, Koerperich H, Dubowy K-O, et al. Impact of gender and age on cardiovascular function late after repair of tetralogy of Fallot: percentiles based on cardiac magnetic resonance. Circ Cardiovasc Imaging 2011; 4: 703-711.

84. Kang IS, Redington AN, Benson LN, et al. Differential regurgitation in branch pulmonary arteries after repair of tetralogy of Fallot: a phase-contrast cine magnetic resonance study. Circulation 2003; 107: 2938-2943.

85. Voser EM, Kellenberger CJ, Buechel ER. Effects of pulmonary regurgitation on distensibility and flow of the branch pulmonary arteries in tetralogy of Fallot. Pediatr Cardiol 2013; 34: 1118-1124.

86. Oosterhof T, van Straten A, Vliegen HW, et al. Preoperative thresholds for pulmonary valve replacement in patients with corrected tetralogy of Fallot using cardiovascular magnetic resonance. Circulation 2007; 116: 545-551.

87. Kutty S, Kuehne T, Gribben P, et al. Ascending aortic and main pulmonary artery areas derived from cardiovascular magnetic resonance as reference values for normal subjects and repaired tetralogy of Fallot. Circ Cardiovasc Imaging 2012; 5: 644-651.

88. Geva T, Vick GW III, Wendt RE, Rokey R. Role of spin echo and cine magnetic resonance imaging in presurgical planning of heterotaxy syndrome. Comparison with echocardiography and catheterization. Circulation 1994; 90: 348-356.

89. Prakash A, Torres AJ, Printz BF, Prince MR, Nielsen JC. Usefulness of magnetic resonance angiography in the evaluation of complex congenital heart disease in newborns and infants. Am J Cardiol 2007; 100: 715-721.

90. Hong YK, Park YW, Ryu SJ, et al. Efficacy of MRI in complicated congenital heart disease with visceral heterotaxy syndrome. J Comput Assist Tomogr 2000; 24: 671-682.

91. Kersting-Sommerhoff BA, Diethelm L, Stanger P, et al. Evaluation of complex congenital ventricular anomalies with magnetic resonance imaging. Am Heart J 1990; 120: 133-142. 
92. Newman B, Feinstein JA, Cohen RA, et al. Congenital extrahepatic portosystemic shunt associated with heterotaxy and polysplenia. Pediatr Radiol 2010; 40: 1222-1230.

93. Gewillig M. The Fontan circulation. Heart 2005; 91: 839-846.

94. Fogel MA, Weinberg PM, Chin AJ, Fellows KE, Hoffman EA. Late ventricular geometry and performance changes of functional single ventricle throughout staged Fontan reconstruction assessed by magnetic resonance imaging. J Am Coll Cardiol 1996; 28: 212-221.

95. Fogel MA. Cardiac magnetic resonance of single ventricles. J Cardiovasc Magn Reson 2006; 8: 661-670.

96. Prakash A, Khan MA, Hardy R, Torres AJ, Chen JM, Gersony WM. A new diagnostic algorithm for assessment of patients with single ventricle before a Fontan operation. J Thorac Cardiovasc Surg 2009; 138: 917-923.

97. Brown DW, Gauvreau K, Powell AJ, et al. Cardiac magnetic resonance versus routine cardiac catheterization before bidirectional Glenn anastomosis in infants with functional single ventricle: a prospective randomized trial. Circulation 2007; 116: 2718-2725.

98. Grosse-Wortmann L, Al-Otay A, Yoo SJ. Aortopulmonary collaterals after bidirectional cavopulmonary connection or Fontan completion: quantification with MRI. Circ Cardiovasc Imaging 2009; 2: 219-225.

99. Robbers-Visser D, Kapusta L, van Osch-Gevers L, et al. Clinical outcome 5 to 18 years after the Fontan operation performed on children younger than 5 years. J Thorac Cardiovasc Surg 2009; 138: 89-95.

100. Beghetti M, Gow RM, Haney I, Mawson J, Williams WG, Freedom RM. Pediatric primary benign cardiac tumors: a 15-year review. Am Heart J 1997; 134: 1107-1114.

101. Kiaffas MG, Powell AJ, Geva T. Magnetic resonance imaging evaluation of cardiac tumor characteristics in infants and children. Am J Cardiol 2002; 89: 1229-1233.

102. O'Donnell DH, Abbara S, Chaithiraphan V, et al. Cardiac tumors: optimal cardiac MR sequences and spectrum of imaging appearances. AJR Am J Roentgenol 2009; 193: 377-387.

103. Beroukhim RS, Prakash A, Buechel ER, et al. Charac-terization of cardiac tumors in children by cardiovascular magnetic resonance imaging: a multicenter experience. J Am Coll Cardiol 2011; 58: 1044-1054.

104. Weinsaft JW, Kim HW, Shah DJ, et al. Detection of left ventricular thrombus by delayed-enhancement cardiovascular magnetic resonance prevalence and markers in patients with systolic dysfunction. J Am Coll Cardiol 2008; 52: 148-157.

105. Hoffmann U, Globits S, Schima W, et al. Usefulness of magnetic resonance imaging of cardiac and paracardiac masses. Am J Cardiol 2003; 92: 890-895.

106. Wilkinson JD, Landy DC, Colan SD, et al. The pediatric cardiomyopathy registry and heart failure: key results from the first 15 years. Heart Fail Clin 2010; 6: 401-413; vii.

107. Gagliardi MG, Bevilacqua M, Di Renzi P, Picardo S, Passariello $\mathrm{R}$, Marcelletti C. Usefulness of magnetic resonance imaging for diagnosis of acute myocarditis in infants and children, and comparison with endomyocardial biopsy. Am J Cardiol 1991; 68: 1089-1091.

108. Karamitsos TD, Francis JM, Myerson S, Selvanayagam JB, Neubauer $\mathrm{S}$. The role of cardiovascular magnetic resonance imaging in heart failure. J Am Coll Cardiol 2009; 54: 1407-1424.

109. Beerbaum P, Sarikouch S, Laser KT, Greil G, Burchert W, Korperich H. Coronary anomalies assessed by whole-heart isotropic 3D magnetic resonance imaging for cardiac morphology in congenital heart disease. J Magn Reson Imaging 2009; 29: 320-327.

110. Vashist S, Singh GK. Acute myocarditis in children: current concepts and manage-ment. Curr Treat Options Cardiovasc Med 2009; 11: 383-391.

111. Grosse-Wortmann L, Roche SL, Yoo SJ, Seed M, Kantor P. Early changes in right ventricular function and their clinical consequences in childhood and adolescent dilated cardiomyopathy. Cardiol Young 2010; 20: 418-425.

112. Mavrogeni S, Papavasiliou A, Spargias K, et al. Myocardial inflammation in Duchenne muscular dystrophy as a precipitating factor for heart failure: a prospective study. BMC Neurol 2010; 10: 33.

113. Olivotto I, Maron BJ, Appelbaum E, et al. Spectrum and clinical significance of systolic function and myocardial fibrosis assessed by cardiovascular magnetic resonance in hypertrophic cardiomyopathy. Am J Cardiol 2010; 106: 261-267.

114. Barker PC, Pasquali SK, Darty S, et al. Use of cardiac magnetic resonance imaging to evaluate cardiac structure, function and fibrosis in children with infantile Pompe disease on enzyme replacement therapy. Mol Genet Metab 2010; 101: 332-337.

115. Marin-Rodriguez C, Ossaba-Velez S, Maroto Alvaro E, Sanchez-Alegre ML. Lack of MR late-enhancement in left ventricular non-compaction in infants and young children. Radiologia 2010; 52: 138-143.

116. Alhabshan F, Smallhorn JF, Golding F, Musewe N, Freedom RM, Yoo SJ. Extent of myocardial non-compaction: comparison between MRI and echocardiographic evaluation. Pediatr Radiol 2005; 35: 1147-1151.

117. Pepe A, Positano V, Santarelli MF, et al. Multigeneous distribution of myocardial iron overload. J Magn Reson Imaging 2006; 23: 662-668.

118. Fogel MA, Weinberg PM, Harris M, Rhodes L. Usefulness of magnetic resonance imaging for the diagnosis of right ventricular dysplasia in children. Am J Cardiol 2006; 97: 1232-1237.

119. Yoo SJ, Grosse-Wortmann L, Hamilton RM. Magnetic resonance imaging assessment of arrhythmogenic right ventricular cardiomyopathy/dysplasia in children. Korean Circ J 2010; 40: 357-367.

120. Marcus FI, McKenna WJ, Sherrill D, et al. Diagnosis of arrhythmogenic right ventricular cardiomyopathy/dysplasia: proposed modification of the Task Force Criteria. Eur Heart J 2010; 31: 806-814.

121. Kostolny M, Tsang V, Nordmeyer J, et al. Rescue surgery following percutaneous pulmonary valve implantation. Eur J Cardiothorac Surg 2008; 33: 607-612.

122. Greil GF, Seeger A, Miller S, et al. Coronary magnetic resonance angiography and vessel wall imaging in children with Kawasaki disease. Pediatr Radiol 2007; 37: 666-673.

123. Brenner DJ, Hall EJ. Computed tomography — an increasing source of radiation exposure. N Engl J Med 2007; 357: 2277-2284.

124. Greil GF, Desai MY, Fenchel M, et al. Reproducibility of freebreathing cardiovascular magnetic resonance coronary angiography. J Cardiovasc Magn Reson 2007; 9: 49-56.

125. Schwitter J, Wacker CM, van Rossum AC, et al. MR-IMPACT: comparison of perfusion-cardiac magnetic resonance with singlephoton emission computed tomography for the detection of coronary artery disease in a multicentre, multivendor, randomized trial. Eur Heart J 2008; 29: 480-489.

126. Schwitter J, Wacker CM, Wilke N, et al. Superior diagnostic performance of perfusion-cardiovascular magnetic resonance versus SPECT to detect coronary artery disease: the secondary endpoints of the multicenter multivendor MR-IMPACT II (magnetic resonance imaging for myocardial perfusion assessment in coronary artery disease trial). J Cardiovasc Magn Reson 2012; 14: 61.

127. Kim RJ, Fieno DS, Parrish TB, et al. Relationship of MRI delayed contrast enhancement to irreversible injury, infarct age, and contractile function. Circulation 1999; 100: 1992-2002.

128. Rathod RH, Prakash A, Powell AJ, Geva T. Myocardial fibrosis identified by cardiac magnetic resonance late gadolinium enhancement is associated with adverse ventricular mechanics and ventricular tachycardia late after Fontan operation. J Am Coll Cardiol 2010; 55: 1721-1728.

129. Babu-Narayan SV, Goktekin O, Moon JC, et al. Late gadolinium enhancement cardiovascular magnetic resonance of the systemic right ventricle in adults with previous atrial redirection surgery for transposition of the great arteries. Circulation 2005; 111: 2091-2098. 